\title{
A Review of Nebivolol Pharmacology and Clinical Evidence
}

\author{
Justin Fongemie ${ }^{1} \cdot$ Erika Felix-Getzik $^{2,3}$
}

Published online: 16 July 2015

(c) Springer International Publishing Switzerland 2015

\begin{abstract}
Nebivolol is a highly selective $\beta_{1}$-adrenergic receptor antagonist with a pharmacologic profile that differs from those of other drugs in its class. In addition to cardioselectivity mediated via $\beta_{1}$ receptor blockade, nebivolol induces nitric oxide-mediated vasodilation by stimulating endothelial nitric oxide synthase via $\beta_{3}$ agonism. This vasodilatory mechanism is distinct from those of other vasodilatory $\beta$-blockers (carvedilol, labetalol), which are mediated via $\alpha$-adrenergic receptor blockade. Nebivolol is approved for the treatment of hypertension in the US, and for hypertension and heart failure in Europe. While $\beta$-blockers are not recommended within the current US guidelines as first-line therapy for treatment of essential hypertension, nebivolol has shown comparable efficacy to currently recommended therapies in lowering peripheral blood pressure in adults with hypertension with a very low rate of side effects. Nebivolol also has beneficial effects on central blood pressure compared with other $\beta$-blockers. Clinical data also suggest that nebivolol may be useful in patients who have experienced erectile dysfunction while on other $\beta$-blockers. Here we review the pharmacological profile of nebivolol, the clinical evidence supporting its use in hypertension as monotherapy, add-on, and combination therapy, and the data demonstrating its positive effects on heart failure and endothelial dysfunction.
\end{abstract}

Erika Felix-Getzik

erika.felix-getzik@mcphs.edu

1 Tufts Medical Center, 800 Washington St., Boston, MA 02111, USA

2 MCPHS University, School of Pharmacy-Boston, 179 Longwood Ave, Boston, MA 02115, USA

3 Newton-Wellesley Hospital, 2014 Washington St, Newton, MA 02462, USA

\section{Key Points}

Nebivolol is the only vasodilatory $\beta_{1}$-selective blocker; the vasodilatory effect is nitric oxidemediated and activated via $\beta_{3}$-agonism.

Nebivolol effectively lowers blood pressure either alone or in combination with other antihypertensive drugs.

The unique pharmacological profile of nebivolol coupled with clinical evidence suggests potential utility in the treatment of hypertension and heart failure with reduced ejection fraction.

\section{Introduction}

Nebivolol (Bystolic ${ }^{\circledR}$ ) is a third-generation, long-acting and highly selective $\beta_{1}$ adrenoreceptor antagonist that also exhibits nitric oxide (NO)-mediated vasodilatory effects via $\beta_{3}$ receptor agonism and reduces oxidative stress [1]. The $\beta_{3}$ receptor agonism differentiates nebivolol from traditional, non-vasodilatory $\beta_{1}$-blockers, such as atenolol, as well as from the vasodilatory $\beta$-blockers carvedilol and labetalol, which act via $\alpha_{1}$ adrenergic antagonism [1]. Nebivolol does not exhibit intrinsic sympathomimetic activity or membrane-stabilizing activity. In the US, nebivolol is indicated for the treatment of hypertension, either as monotherapy or in combination with other antihypertensive agents, and has been evaluated for the treatment of chronic heart failure. 
In this article, we discuss the unique pharmacology of nebivolol and review its clinical efficacy and safety.

\section{Literature Search Methodology}

Discussion of safety and efficacy was limited to hypertension, heart failure (HF), and erectile dysfunction. Literature searches, conducted in the period OctoberDecember 2014, were performed using the PubMed database (without the limit in regard to date), looking for terms 'nebivolol', 'hypertension', 'blood pressure', 'heart failure', and 'erectile dysfunction' in titles and abstracts, and restricting the results to studies in humans and nonreview articles in English language. Both authors examined the resulting lists of abstracts and excluded those that did not fit the scope of the article.

\section{Pharmacology of Nebivolol}

$\beta$-Blockers are a heterogeneous class of compounds that have evolved from first-generation, nonselective agents (e.g., propranolol) to second-generation, cardioselective $\beta_{1}$-blockers (e.g., atenolol, bisoprolol, metoprolol) to third-generation compounds that combine $\beta$-blockade with vasodilatory properties (e.g., carvedilol, labetalol, nebivolol) [2]. Nebivolol is highly $\beta_{1}$-selective at doses $\leq 10 \mathrm{mg}$ per day, with approximately 320 -fold greater affinity for $\beta_{1}$ than $\beta_{2}$ receptors in the cells of human myocardium [3]. While the vasodilatory properties of carvedilol and labetalol are mediated by $\alpha$-adrenergic receptor blockade [4], nebivolol exerts these effects by increasing endothelium-derived $\mathrm{NO}$ via stimulatory effect on endothelial nitric oxide synthase (NOS), mediated through $\beta_{3}$ agonism [5-8].

The distinct pharmacologic profile of nebivolol is associated with a number of hemodynamically relevant effects: (1) $\beta_{1}$-blockade, which decreases resting and exercise heart rate, myocardial contractility, and both systolic and diastolic blood pressure; (2) NO-mediated vasodilation that results in a decrease in peripheral vascular resistance, an increase in stroke volume and ejection fraction, and maintenance of cardiac output [1]; (3) vasodilation and reduced oxidative stress that are thought to contribute to the neutral and possibly beneficial effects of nebivolol on glucose and lipid metabolism [9, 10]; and (4) reduced platelet volume and aggregation [11, 12]. These attributes suggest a potentially broad usefulness for nebivolol in the treatment of hypertension and chronic heart failure.

\section{Clinical Pharmacokinetics of Nebivolol}

The absolute bioavailability of nebivolol is unknown. The drug is $98 \%$ protein bound, primarily to albumin, and reaches a peak concentration after 1.5-4 h. Nebivolol is metabolized in the liver, mainly via direct glucuronidation and secondarily through cytochrome P450 2D6 (CYP450 2D6). The active metabolites, hydroxyl and glucuronides, contribute to the $\beta$-blocking effect of nebivolol. As with other drugs metabolized via CYP450 2D6, genetic differences can impact metabolism, elimination half-life, excretion, and clinical and adverse effects of nebivolol. It should, however, be noted that data suggests that in CYP450 2D6 poor metabolizers, no dose adjustment is needed as the clinical effect and safety profiles are similar to that of extensive metabolizers [13].

The elimination half-life of nebivolol is typically $12 \mathrm{~h}$, but is prolonged to $19 \mathrm{~h}$ in those who are poor metabolizers. Excretion of nebivolol is $35 \%$ through urine and $44 \%$ via feces in average metabolizers; patients who are poor metabolizers excrete $67 \%$ of the drug in urine and $13 \%$ in feces [13].

\section{Endothelial and Hemodynamic Effects}

Endothelial dysfunction caused by oxidative stress has been implicated in the development of hypertension [14]. A number of studies have demonstrated favorable endothelial effects of nebivolol versus non-vasodilatory $\beta_{1}$-selective blockers (atenolol, metoprolol). For example, nebivolol was shown to be superior to atenolol in improving small artery distensibility index [15], parameters of oxidative stress [16], flow-mediated dilation of the brachial artery $[17,18]$, and plasma concentration of asymmetric dimethyl arginine (ADMA) [18], an endogenous inhibitor of NO production that has been associated with cardiovascular risk [19]. Compared with metoprolol, nebivolol reduces plasma ADMA levels and the augmentation index (AIx) [20], a surrogate measure of arterial stiffness that is also associated with cardiovascular risk [21]. However, the AIx benefits compared with metoprolol may not extend to individuals with hypertension and diabetes mellitus who are receiving maximal tolerated doses of renin-angiotensinaldosterone system (RAAS) blockers [22]. Of note, a 12-month randomized trial that compared the effects of nebivolol and metoprolol on a number of hemodynamic and biochemical parameters found no difference in AIx and ADMA levels between the two groups, but demonstrated that only nebivolol had a beneficial effect on oxidative stress [23] and significantly reduced central systolic blood pressure (SBP), diastolic blood pressure (DBP), pulse 
pressure (PP), and left ventricular wall thickness [24]. Whether these positive effects translate to improvement of clinical outcomes remains to be seen.

Despite the absence of data from large outcome studies with nebivolol, the vascular effects and hemodynamic profile suggest potential advantages of nebivolol compared with non-vasodilating $\beta_{1}$ selective and nonselective $\beta$-blockers in the treatment of hypertension. Central hemodynamic effects are important to highlight, because they are independent predictors of cardiovascular morbidity and mortality $[25,26]$ and because they may be a key reason why traditional $\beta$-blockers (e.g., atenolol) have been associated with smaller reductions in cardiovascular morbidity and mortality than other antihypertensive classes (e.g., calcium channel blockers) [27].

For example, studies have shown that, relative to atenolol and metoprolol succinate, nebivolol improves central hemodynamics and reduces arterial stiffness in patients with hypertension, regardless of similar reductions in peripheral DBP and SBP [24, 28-30]. In one study, 40 individuals with untreated essential hypertension were randomized to atenolol $50 \mathrm{mg} /$ day or nebivolol $5 \mathrm{mg} /$ day for 4 weeks; treatment with nebivolol reduced aortic PP to a significantly greater extent than atenolol ( -16 vs $-11 \mathrm{mmHg} ; p=0.04)$ [29]. Though both compounds significantly reduced aortic pulse wave velocity (PWV) from baseline, only nebivolol treatment was associated with a significant reduction from baseline in AIx (from 35 to $28 \% ; p<0.05)$. Furthermore, PP amplification, a hemodynamic indicator inversely associated with large artery stiffness and peripheral arterial resistance [27], was significantly increased with nebivolol treatment and significantly decreased with atenolol. Similar results were obtained in a randomized, cross-over study of 16 patients with untreated isolated systolic hypertension (ISH) [28] who received atenolol $50 \mathrm{mg} / \mathrm{day}$, nebivolol $5 \mathrm{mg} / \mathrm{day}$, and placebo for 5 weeks each. The significant reductions in aortic PWV compared with placebo were similar between nebivolol and atenolol, but nebivolol treatment was associated with a smaller increase in AIx compared with atenolol (6 vs $10 \% ; p=0.04)$. The aortic PP after treatment with nebivolol was similar to that of placebo, but was significantly lower compared with treatment with atenolol (50 vs $54 \mathrm{mmHg} ; p=0.02$ ) [28].

A few more recent publications also provided evidence of improvement in central hemodynamics with nebivolol. For example, in a trial that randomized 45 patients with stage I hypertension to nebivolol $(10 \mathrm{mg} /$ day $)$, lifestyle modifications, or the combination of nebivolol and lifestyle modifications for 12 weeks, the $\beta$-stiffness index, a bloodpressure-independent measure of arterial stiffness, decreased $(p<0.01)$, and arterial compliance increased $(p=0.02)$ [31]. Another trial randomized 138 patients with mild to moderate hypertension to atenolol (50-100 mg/day) or nebivolol $(5 \mathrm{mg} /$ day) for 10 weeks, with hydrochlorothiazide $25 \mathrm{mg} /$ day added on if necessary to control blood pressure. After adjusting for heart rate, the mean between-group difference in AIx was $2.4 \%$ $(p=0.041)$, with nebivolol increasing AIx to a lesser extent than atenolol [30]. Lastly, in a trial that compared nebivolol (5 mg/day) with metoprolol succinate (50-100 mg/day) in patients with mild to moderate hypertension, nebivolol reduced mean central PP from baseline significantly more than metoprolol $(-6.2$ vs $-0.3 \mathrm{mmHg} ; p=0.01$ ), with no difference from baseline with either agent in PP amplification, PWV, or AIx [24]. The differential effects on aortic PP between nebivolol and atenolol or metoprolol succinate observed in these studies are similar in magnitude to those between the amlodipineand atenolol-based therapies reported in the Conduit Artery Function Evaluation (CAFE) study [32], a substudy of the Anglo-Scandinavian Cardiac Outcomes Trial (ASCOT; $N=19,257$ ), which demonstrated a greater reduction in major cardiovascular events and mortality with the amlodipine-based than atenolol-based regimen, despite a similar decrease in brachial blood pressure [33]. The question of whether the more favorable effects of nebivolol on central aortic pressure versus those of non-vasodilating $\beta$-blockers translate into improved clinical outcomes would have to be tested in large primary or secondary prevention trials.

As mentioned previously, nebivolol is a $\beta_{1}$-selective blocker that exerts a vasodilatory effect through stimulation of endothelial NOS [1]. The contribution of vasodilation to the overall antihypertensive effect of nebivolol was recently assessed in a small, double-blind, placebo-controlled cross-over study of 20 patients with autonomic failure [34], who are devoid of adrenergic input in blood pressure control and are therefore characterized by an impaired baroreceptor function, as manifested through orthostatic hypotension and supine hypertension. In that trial, nebivolol $(5 \mathrm{mg})$ but not metoprolol $(50 \mathrm{mg})$ lowered night-time SBP $(p=0.036)$ and DBP $(p<0.001)$ versus placebo, effects that were driven by the subgroup of individuals who also responded to sildenafil $(25 \mathrm{mg})$ [34]. This reduction in blood pressure that is independent of $\beta_{1}$-antagonism is consistent with the hypothesis that NO-mediated vasodilation contributes significantly to an overall antihypertensive effect of nebivolol.

While nebivolol's NO-mediated vasodilatory effects may be favorable, there is concern about the development of nitrate tolerance and the adverse endothelial effects that are associated with the continuous long-term use of organic nitrates [1]. In a small study of 16 healthy patients who were taking either nebivolol $5 \mathrm{mg}$ or 
placebo for 8 days, forearm blood flow was measured before and after $5 \mathrm{~min}$ of intravenous nitroglycerin administration ( $4 \mu \mathrm{g} / \mathrm{kg}$ body weight $/ \mathrm{min}$ ). The blood flow increase in those receiving nebivolol (96\%) was significantly greater than the increase observed in those receiving placebo $(54 \% ; p<0.05)$ [35]. This reduction in nitrate tolerance following nebivolol treatment remains to be confirmed in larger trials.

\section{Nebivolol for the Treatment of Hypertension}

Nebivolol at doses of $1.25-40 \mathrm{mg} /$ day has been evaluated for the treatment of hypertension, both as monotherapy and in combination with other classes of antihypertensive agents (Table 1). It is provided in tablets of $2.5,5,10$, and $20 \mathrm{mg}$; for most patients, it is recommended to start with a dose of $5 \mathrm{mg}$ daily, which can be titrated up to $40 \mathrm{mg} /$ day at 2-week intervals [13]. A lower initial dose of $2.5 \mathrm{mg} /$ day is recommended in patients with moderate hepatic and/or severe renal impairment. However, nebivolol should be avoided in patients with severe hepatic impairment and has not been studied in patients who are receiving dialysis [13]. While nebivolol monotherapy is approved in the US for lowering blood pressure, recent treatment guidelines from the American Society of Hypertension and the International Society of Hypertension [36], as well as the Panel Members Appointed to the Eighth Joint National Committee (JNC 8) [37], do not recommend first-line use of $\beta$-blockers in patients with essential hypertension. The rationale provided by JNC 8 is based on results from several randomized controlled trials in which either $\beta$-blockers performed similarly to the recommended therapies of thiazide-type diuretics, calcium channel blockers (CCBs), angiotensin-converting enzyme inhibitors (ACEIs), or angiotensin II receptor blockers (ARBs) or firm conclusions could not be made from the evidence [37]. Additionally, the results of one trial comparing a $\beta$-blocker (atenolol) and an ARB (losartan) showed that despite similar reductions in blood pressure, losartan prevented more cardiovascular morbidity and mortality than atenolol [38]. One meta-analysis and one systematic review, which were not included as supporting evidence for recommendations in JNC 8, have also shown no benefit of $\beta$-blockers compared with other antihypertensives in reducing cardiovascular morbidity and mortality, along with an increased risk of stroke [39, 40]. It has been noted that atenolol, a non-vasodilating $\beta_{1}$-selective blocker, was used in the large majority of studies included in these meta-analyses, and the finding therefore may not be generalizable to third-generation, vasodilatory $\beta$-blockers such as carvedilol and nebivolol [41].

\subsection{Monotherapy Data}

\subsubsection{Pivotal Trials}

The approval of nebivolol for the treatment of hypertension in the US was based upon evidence of its efficacy in three large, randomized, placebo-controlled dose-ranging studies in adults with hypertension [42-44]. In each study, patients were randomized to 12 weeks of double-blind treatment with various fixed doses of nebivolol or placebo following a 4- to 6-week single-blind, placebo washout period. The primary efficacy parameter was change from baseline in mean trough DBP; secondary parameters included change from baseline in mean trough SBP and a response rate at endpoint, defined as the proportion of patients with mean trough DBP $<90 \mathrm{mmHg}$ or an absolute reduction of $\geq 10 \mathrm{mmHg}$ from baseline. In total, over 2000 patients were included, with one trial consisting of black participants only [43]. Results from each study consistently showed significant reductions in DBP with nebivolol doses ranging from 5 to $40 \mathrm{mg}$ daily and reductions in SBP at higher daily doses (10-20 mg), as well as significantly higher response rates compared with placebo. A dose-response effect in terms of both SBP and DBP reduction was observed [42-44].

\subsubsection{Pooled Analyses}

Post-hoc, pooled analyses from the three pivotal trials $(N=2016)$ discussed above were conducted to assess efficacy, safety, and tolerability with a greater statistical power [45], as well as to explore the effects of nebivolol on patients by age [46] and body mass index (BMI) [47]. The pooled data demonstrated a significant effect of nebivolol over placebo on both DBP and SBP for all clinically recommended dosages (5-40 mg/day), and showed that nebivolol is generally safe and well tolerated [45]. The discontinuation rate due to adverse events (AEs) among nebivolol-treated patients (all dosages) was low $(2.6 \%$ ) and comparable to that observed with placebo (2.0\%). The most common AEs in patients receiving nebivolol were headache (7.1 vs $5.9 \%$ for placebo), fatigue (3.6 vs $1.5 \%$ ), and dizziness (2.9 vs $2.0 \%$ ).

Similar efficacy results were reported in a pooled analysis of 205 placebo-treated patients and 1380 patients treated with nebivolol dosages of 5,10 , or $20 \mathrm{mg} /$ day, stratified by age (22-46, 47-53, 54-62, and 63-84 years) [46]. In all age groups, each nebivolol dose significantly reduced DBP compared with placebo. All dosages of nebivolol in all age groups significantly lowered SBP versus placebo, with the exception of the oldest age group, in whom a significant effect was observed only with the $20 \mathrm{mg} /$ day dosage [46]. A pooled analysis examining the 


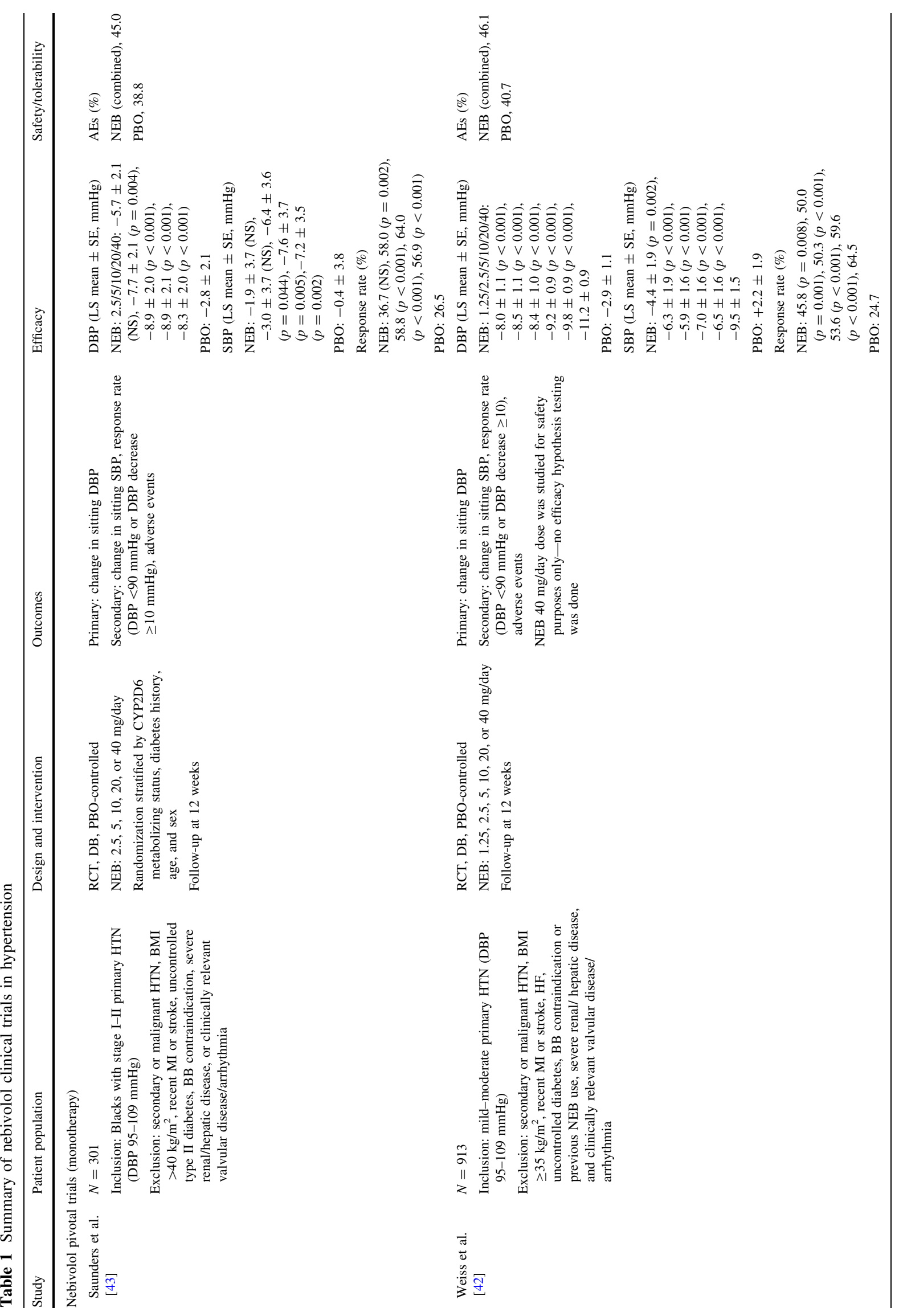




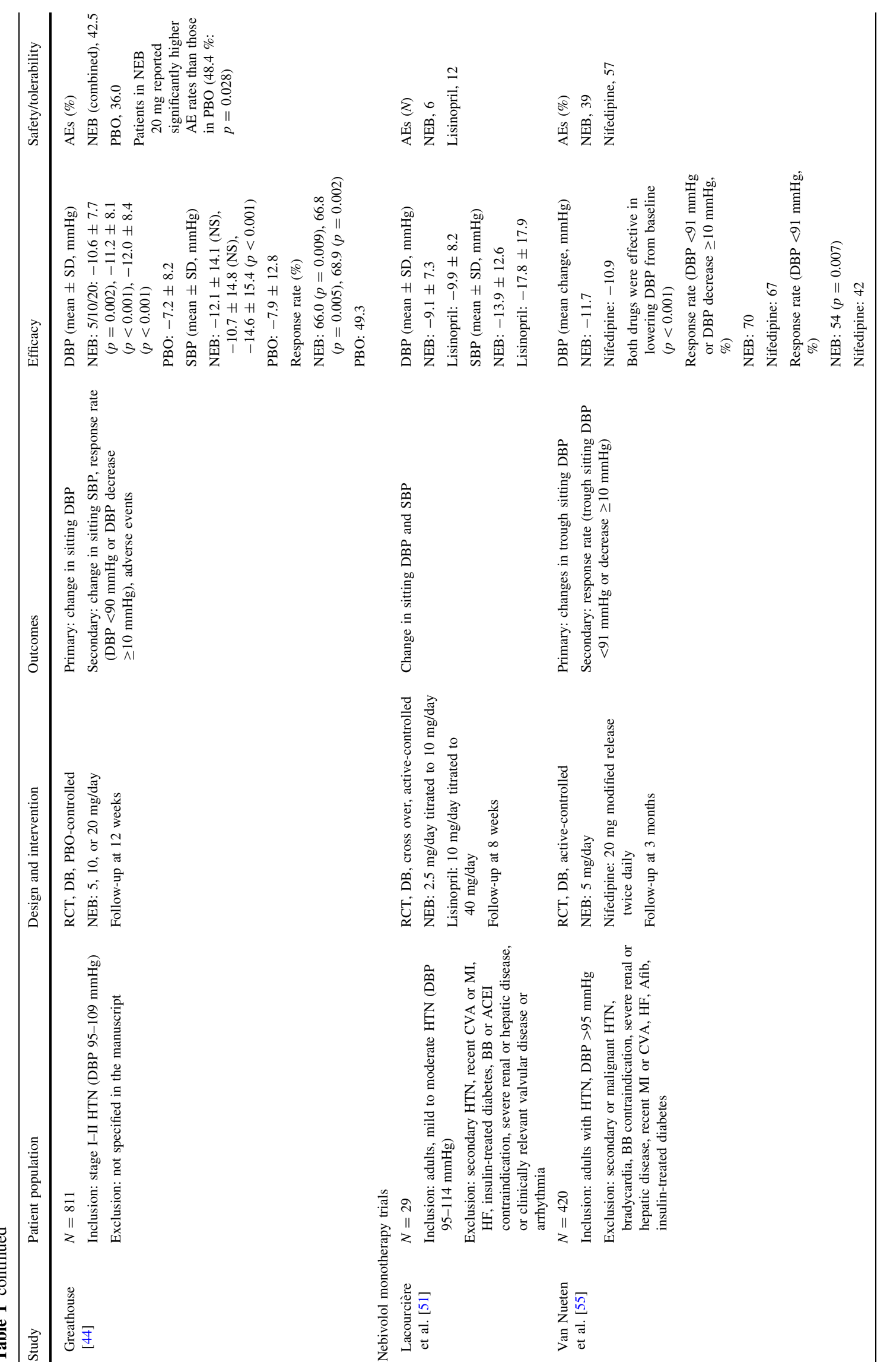




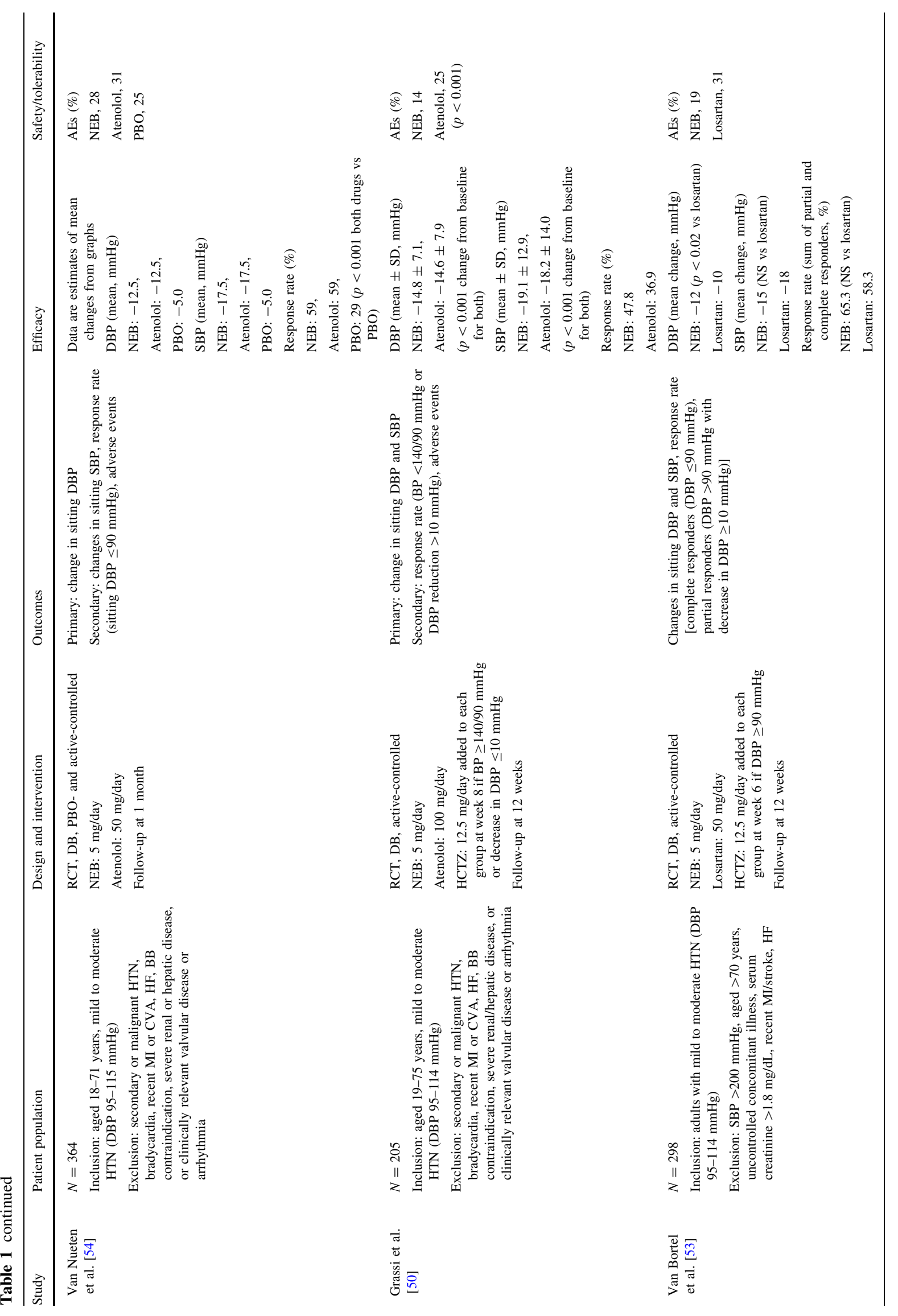




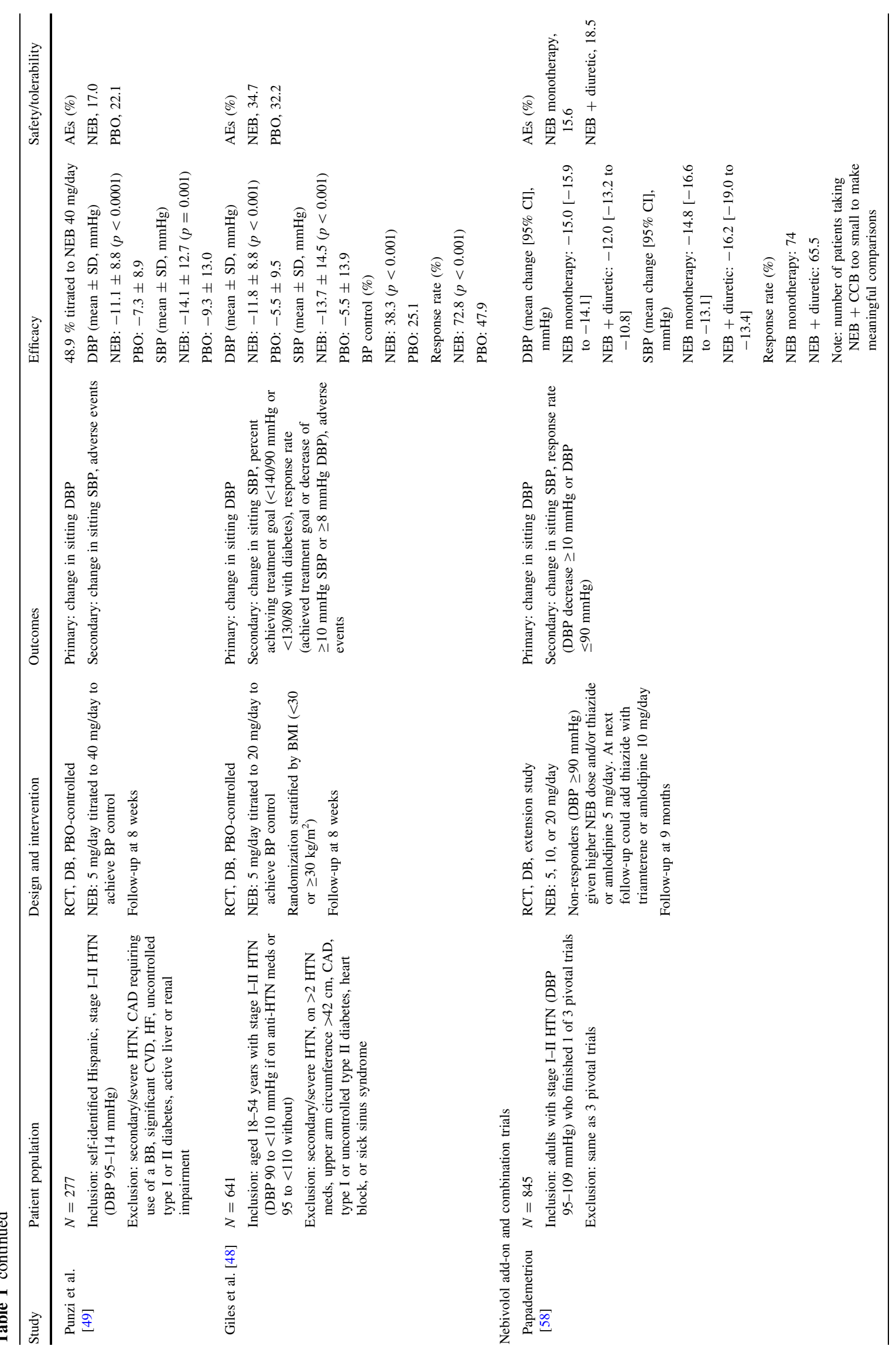




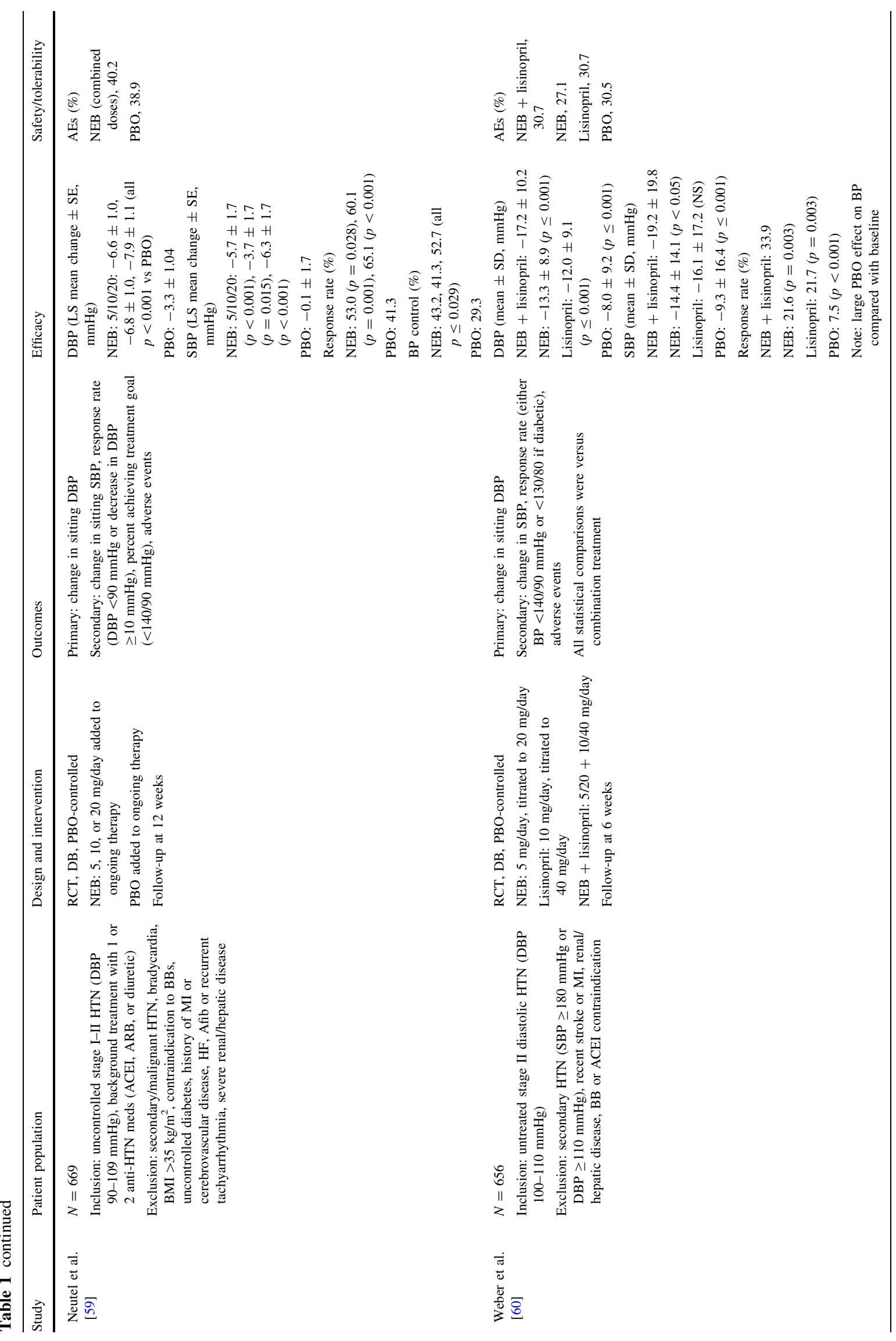




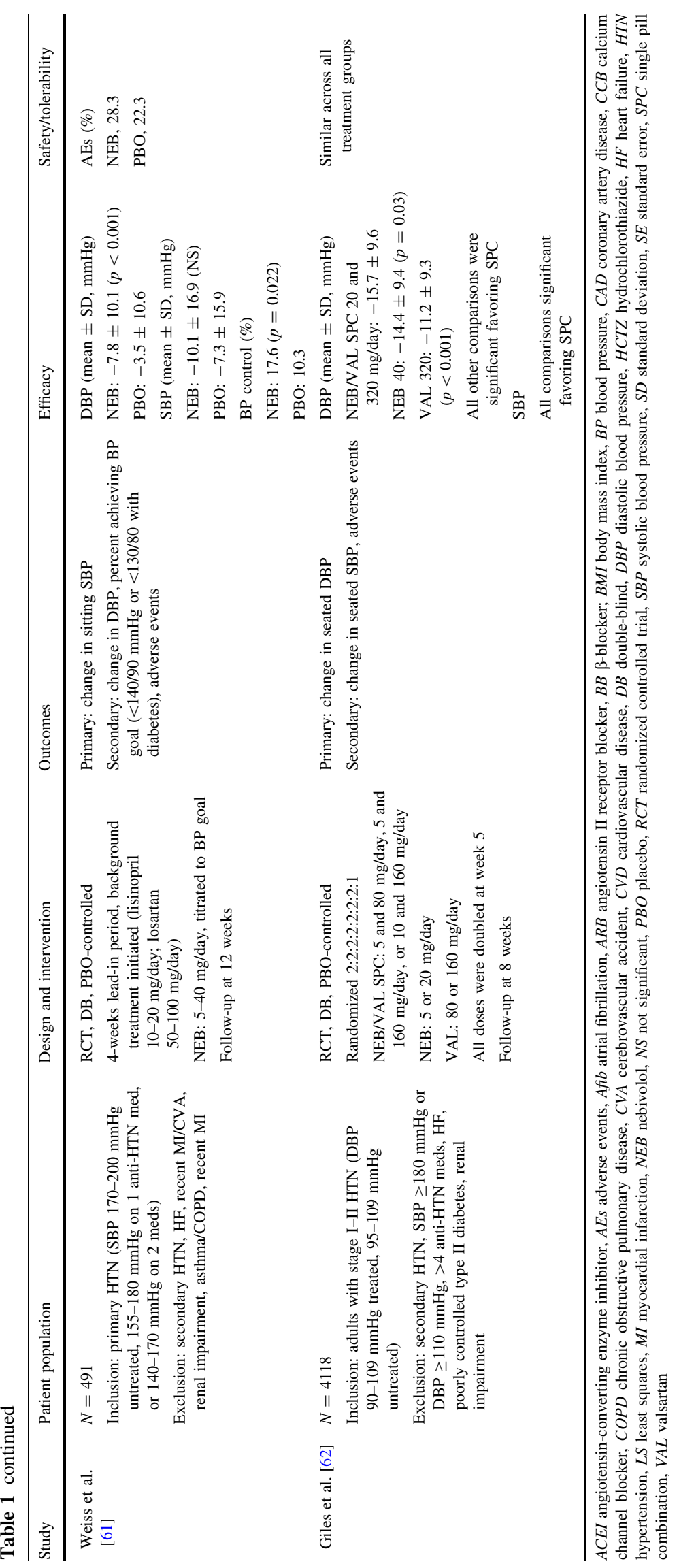


effects of nebivolol treatment on patients stratified by baseline BMI $\left[<30 \mathrm{~kg} / \mathrm{m}^{2}\right.$ (non-obese) or BMI $\geq 30 \mathrm{~kg} / \mathrm{m}^{2}$ and $\leq 35 \mathrm{~kg} / \mathrm{m}^{2}$ (moderately obese)] demonstrated that nebivolol at doses ranging from 5 to $40 \mathrm{mg} /$ day significantly reduced DBP and SBP versus placebo in both BMI categories [47]. Response rates at the end of treatment were significantly higher for all nebivolol dosages $\geq 2.5 \mathrm{mg} /$ day in the non-obese group and $\geq 5 \mathrm{mg} /$ day in the moderately obese group [47].

\subsubsection{Monotherapy Trials in Special Populations}

Placebo-controlled trials of nebivolol monotherapy in specific patient populations include one conducted in younger patients (age range, 18-54 years; mean age, 45.3 years) with stage 1 or stage 2 hypertension in which nebivolol significantly reduced DBP (change from baseline: $-11.8 \mathrm{mmHg}$ vs $-5.5 \mathrm{mmHg} ; p<0.001)$ and SBP (change form baseline: $-13.7 \mathrm{mmHg}$ vs $-5.5 \mathrm{mmHg}$; $p<0.001$ ), compared with placebo [48]. A trial conducted in self-identified Hispanics also demonstrated a significant decrease in DBP (change from baseline: $-11.1 \mathrm{mmHg}$ vs $-7.3 \mathrm{mmHg} ; \quad p<0.0001)$ and SBP $(-14.1 \mathrm{mmHg}$ vs $-9.3 \mathrm{mmHg} ; p=0.001)$ with nebivolol treatment, compared with placebo [49]. Finally, in the pivotal trial conducted in African-Americans, nebivolol significantly reduced both DBP at all doses $\geq 5 \mathrm{mg}$ ( $5 \mathrm{mg}, p=0.004$; $10,20$, and $40 \mathrm{mg}, p<0.001)$ and SBP at all doses $\geq 10 \mathrm{mg}$ (10 mg, $p=0.044 ; 20 \mathrm{mg}, p=0.005 ; 40 \mathrm{mg}$, $p=0.002)$ compared with placebo [43]

\subsection{Nebivolol Versus Active Comparators}

The antihypertensive efficacy of nebivolol monotherapy has been established in controlled trials with active comparators [24, 28-30, 50-54]. Two such studies compared nebivolol to the non-vasodilatory $\beta_{1}$-selective blocker, atenolol, in adults with mild to moderate hypertension [50, 54]. In one study, 364 patients were randomized to nebivolol $5 \mathrm{mg} /$ day, atenolol $50 \mathrm{mg} /$ day, or placebo. Results indicated that both active compounds were statistically superior to placebo and comparable to each other in terms of reducing DBP and SBP [54]. In another study, 205 patients were randomized to nebivolol $5 \mathrm{mg} /$ day or atenolol $100 \mathrm{mg} /$ day, and the diuretic hydrochlorothiazide (HCTZ; $12.5 \mathrm{mg} /$ day) was added to either treatment arm after 8 weeks if BP control was not achieved (approximately $20 \%$ in each group required concomitant HCTZ treatment) [50]. Comparable to the trial discussed previously, treatment with nebivolol and atenolol resulted in similarly significant antihypertensive effects versus baseline, with reductions in DBP and SBP of $-14.8 \mathrm{mmHg}$ and $-19.1 \mathrm{mmHg}$ for nebivolol, and $-14.6 \mathrm{mmHg}$ and
$-18.2 \mathrm{mmHg}$ for atenolol $(p<0.001$, all). Addition of HCTZ resulted in an equal additional antihypertensive effect in both groups versus monotherapy ( $p<0.03$ ) [50].

Nebivolol was also tested in active-controlled trials with ACEIs, ARBs, and CCBs [51-53, 55]. In an 8-week, crossover, double-blind, randomized trial, significant and comparable reductions in DBP and SBP were observed with nebivolol (2.5-10 mg/day) and lisinopril (10-40 mg/day) [51]. In a 12-week, randomized, doubleblind trial, nebivolol ( $5 \mathrm{mg} /$ day) significantly reduced DBP $(-12 \mathrm{mmHg}$ at 6 and 12 weeks) versus losartan $(50 \mathrm{mg} /$ day; $-8 \mathrm{mmHg}$ and $-10 \mathrm{mmHg}$ after 6 and 12 weeks, respectively) [53], with significantly more losartan-treated patients requiring add-on HCTZ (12.5 mg/day) treatment to achieve BP control. Similar significant reductions in SBP from baseline were observed with nebivolol and losartan. In two separate trials, the efficacy of nebivolol was comparable in lowering SBP and DBP with the dihydropyridine $\mathrm{CCBs}$, sustained-release nifedipine, and amlodipine, with the exception that more patients required the addition of $\mathrm{HCTZ}$ to achieve $\mathrm{BP}$ control in the trial with amlodipine $[52,55]$.

\subsection{Add-On and Combination Trials}

Many patients with hypertension require more than a single antihypertensive agent to achieve target blood pressure [56, 57]. The efficacy of nebivolol monotherapy and in combination with other antihypertensive therapies was studied in a double-blind 9-month extension study [58] in which 845 patients from one of three 12-week studies [42-44] received nebivolol monotherapy $[N=607(72 \%)]$, nebivolol plus diuretic $[N=206(24 \%)]$, nebivolol plus amlodipine $(N=21(2 \%)]$, or nebivolol plus other antihypertensive medication $[N=11(1 \%)]$. Significant decreases in mean DBP and SBP from baseline were observed with nebivolol monotherapy $(-15.0$ and $-14.8 \mathrm{mmHg}$, respectively) and nebivolol plus diuretic $(-12.0$ and $-16.2 \mathrm{mmHg}$, respectively). Overall, $74 \%$ of patients treated with nebivolol monotherapy and $65.5 \%$ of those treated with nebivolol plus diuretic responded to treatment (DBP $\leq 90 \mathrm{mmHg}$ or decrease in DBP $\geq 10 \mathrm{mmHg}$ ) [58]. In a separate trial in patients with uncontrolled stage 1 or stage 2 hypertension, 12 weeks of treatment with nebivolol $(5,10$ or $20 \mathrm{mg} /$ day) added to ongoing antihypertensive therapy (ACEI, ARB, and/or diuretic) significantly reduced blood pressure versus placebo (placebo-subtracted least squares mean reduction range: $\mathrm{DBP}-3.3$ to $-4.6 \mathrm{mmHg}, p<0.001$ all; $\mathrm{SBP}-3.7$ to $-6.2 \mathrm{mmHg}, p \leq 0.015$ all) and resulted in significantly more responders (range: $53.0-65.1$ vs $41.3 \%$; $p \leq 0.028$ all) [59].

In a 6-week double-blind, placebo-controlled trial in patients with stage 2 hypertension [60], the effect of a 
nebivolol/lisinopril (5-20 and 10-40 mg/day, respectively) combination on baseline-to-endpoint change in DBP (primary efficacy parameter) was significantly greater than those of placebo $(p<0.001)$, nebivolol alone $(5-20 \mathrm{mg} / \mathrm{day}$, $p=0.001)$, and lisinopril alone $(10-40 \mathrm{mg} / \mathrm{day}, p<0.001)$. The change from baseline in SBP with the nebivolol/lisinopril combination was also significantly reduced compared with placebo $(p<0.001)$ and nebivolol $(p<0.05)$, but not versus lisinopril monotherapy [60]. A separate 12-week trial [61] investigated nebivolol (5-40 mg/day) as add-on therapy to lisinopril (10-20 mg/day) or losartan (50-100 mg/day) in patients with untreated or uncontrolled hypertension treated with lisinopril or losartan. Nebivolol as add-on therapy significantly reduced mean DBP versus placebo (-7.8 vs $-3.5 \mathrm{mmHg} ; p<0.001)$, while the effects on SBP did not reach significance $(-10.1$ vs $-7.3 \mathrm{mmHg})$. The authors suggested that a relatively strong placebo effect in this trial may limit data interpretation [61].

Finally, an 8-week double-blind trial compared a singlepill combination (SPC) of nebivolol and valsartan (10/160, $10 / 320$, and $20 / 320 \mathrm{mg} /$ day) in patients with stage 1 or stage 2 hypertension [62] with nebivolol (10 or $40 \mathrm{mg} /$ day), valsartan (160 or $320 \mathrm{mg} /$ day), and placebo. All comparisons for change in DBP and SBP were significant in favor of the SPCs versus their monotherapy components [62].

\section{Nebivolol for the Treatment of Heart Failure (HF)}

According to the 2013 American College of Cardiology Foundation (ACCF) and the American Heart Association (AHA) guidelines, the current standard treatment for HF is a combination of a RAAS inhibitor (an ACEI or an ARB) and a $\beta$-blocker [63]. $\beta$-blockers may improve the condition of patients with $\mathrm{HF}$ by reducing the myocardial workload (via lower heart rate) and by decreasing sudden death through reduction of arrhythmias [64]. The three $\beta$-blockers currently recommended by the ACCF/AHA guidelines-bisoprolol, carvedilol, and metoprolol succinate-were chosen based on observed reductions in mortality in multiple large-scale clinical studies [65-67]. Patients with fluid retention can also be given a loop diuretic. In the case of patients who have left ventricular ejection fraction (LVEF) of $\leq 35 \%$, an aldosterone antagonist should be considered [63].

Elevated adrenergic activity in the heart muscle after injury causes a progressive degeneration that leads to left ventricular dysfunction and reduced LVEF. It follows that an adrenergic blockade would slow this degeneration and increase survival [65], and numerous studies have shown that treatment regimens that include a $\beta$-blocker can reduce
HF-related mortality [66-68]. A recent meta-analysis on $\beta$ blocker use in HF patients with reduced ejection fraction (HFrEF) showed that $\beta$-blocker treatment confers a significant mortality reduction compared with placebo or active comparator (odds ratio [95\% confidence interval (CI)]: 0.71 [0.64-0.80]; $p<0.001$ ) [68]. Improvements up to $4 \%$ were observed in LVEF, as well as reductions in sudden deaths and deaths from cardiovascular disease; these benefits occurred regardless of the treatment duration or $\beta$-blocker type [68]. However, the mechanisms of action through which $\beta$-blockers confer benefits in HF may not be limited to $\beta$-adrenergic blockade. The vasodilatory agents (nebivolol, carvedilol, labetalol) can reverse hypertensionrelated arterial remodeling [1, 2, 69] and arterial stiffness, both strongly associated with HF [70]. The exact role of those mechanisms, such as NO-mediated vasodilation in case of nebivolol $[1,69]$, would have to be examined in dedicated trials [64].

\subsection{Nebivolol Studies in HF}

Although nebivolol is currently not approved by the US Food and Drug Administration (FDA) for HF treatment, numerous studies suggest that it may be effective in treating patients with HF (Table 2). For example, in a randomized, double-blind study conducted in patients with uncomplicated hypertension, nebivolol (5 $\mathrm{mg}$ /day) preserved cardiac output while decreasing peripheral resistance [71]. Additionally, several studies conducted in patients with hypertension have shown that the hemodynamic effects of nebivolol are similar to or more favorable than those associated with the three ACCF/AHA-recommended $\beta$ blockers [70-72]. While these studies included individuals with hypertension but without HF, the observed hemodynamic effects indicate that nebivolol may have favorable effects in HF. Furthermore, results from a small-scale HF study indicate that, in patients with HFrEF, nebivolol significantly lowers heart rate and SBP and improves stroke volume [72]. Results from another study suggest that nebivolol may be beneficial over metoprolol tartrate as it does not invoke the same negative hemodynamics seen with initiation of metoprolol tartrate [increased pulmonary arterial pressure (PAP), pulmonary capillary wedge pressure (PCWP) and decreased cardiac output (CI)] [73]. In a 12-month, randomized trial $(N=26)$ in patients with $\mathrm{HF}$ and preserved LVEF (HFpEF), hemodynamic improvements and exercise tolerance with nebivolol were greater than those observed with atenolol [74]. Finally, in the CARNEBI (Multiparametric comparison of CARvedilol, vs NEbivolol, vs BIsoprolol in moderate heart failure) cardiopulmonary trial, 70 patients with moderate HF who were given carvedilol, nebivolol, and bisoprolol for 2 months each showed improvements on measures of lung diffusion 


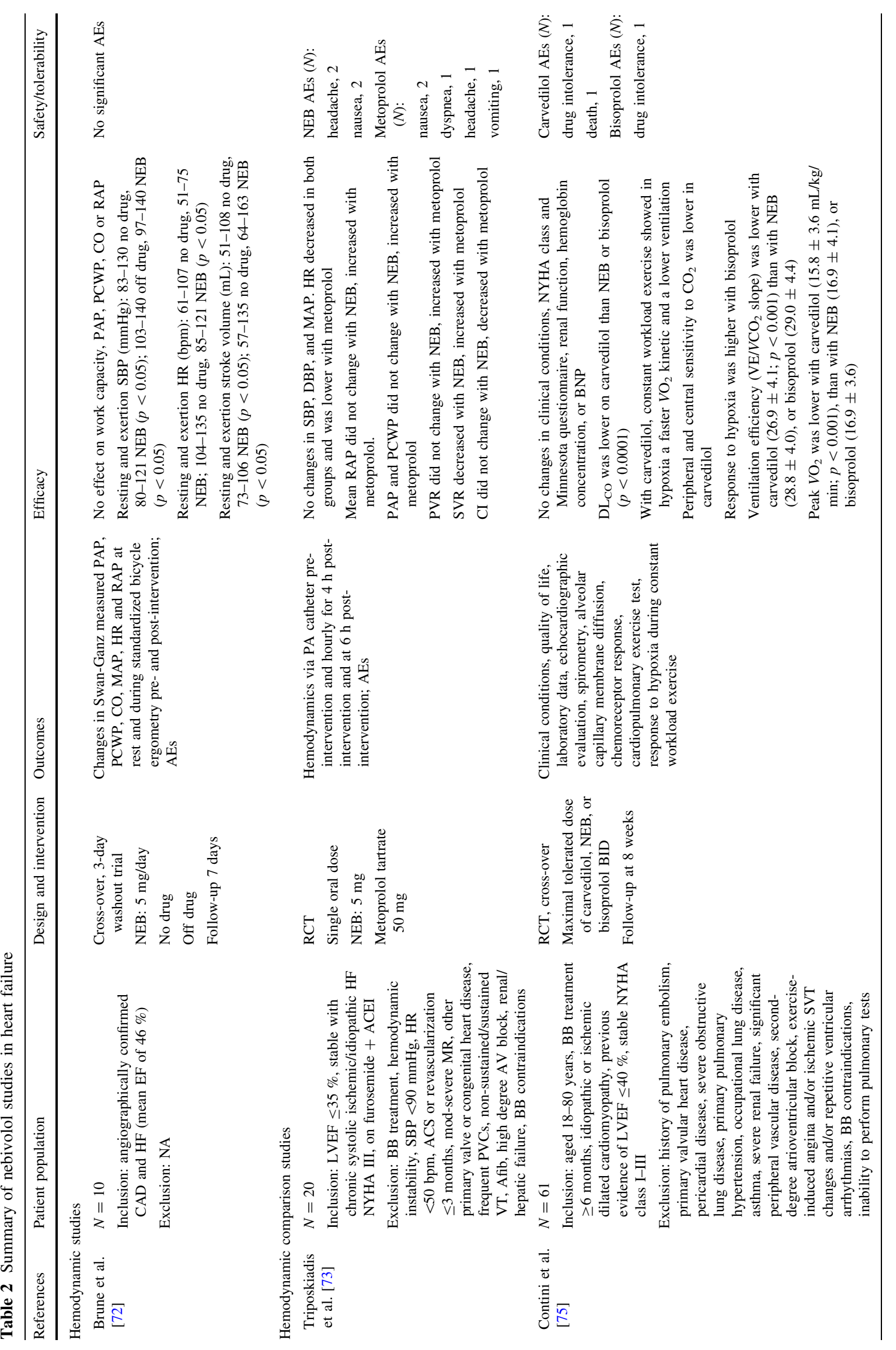




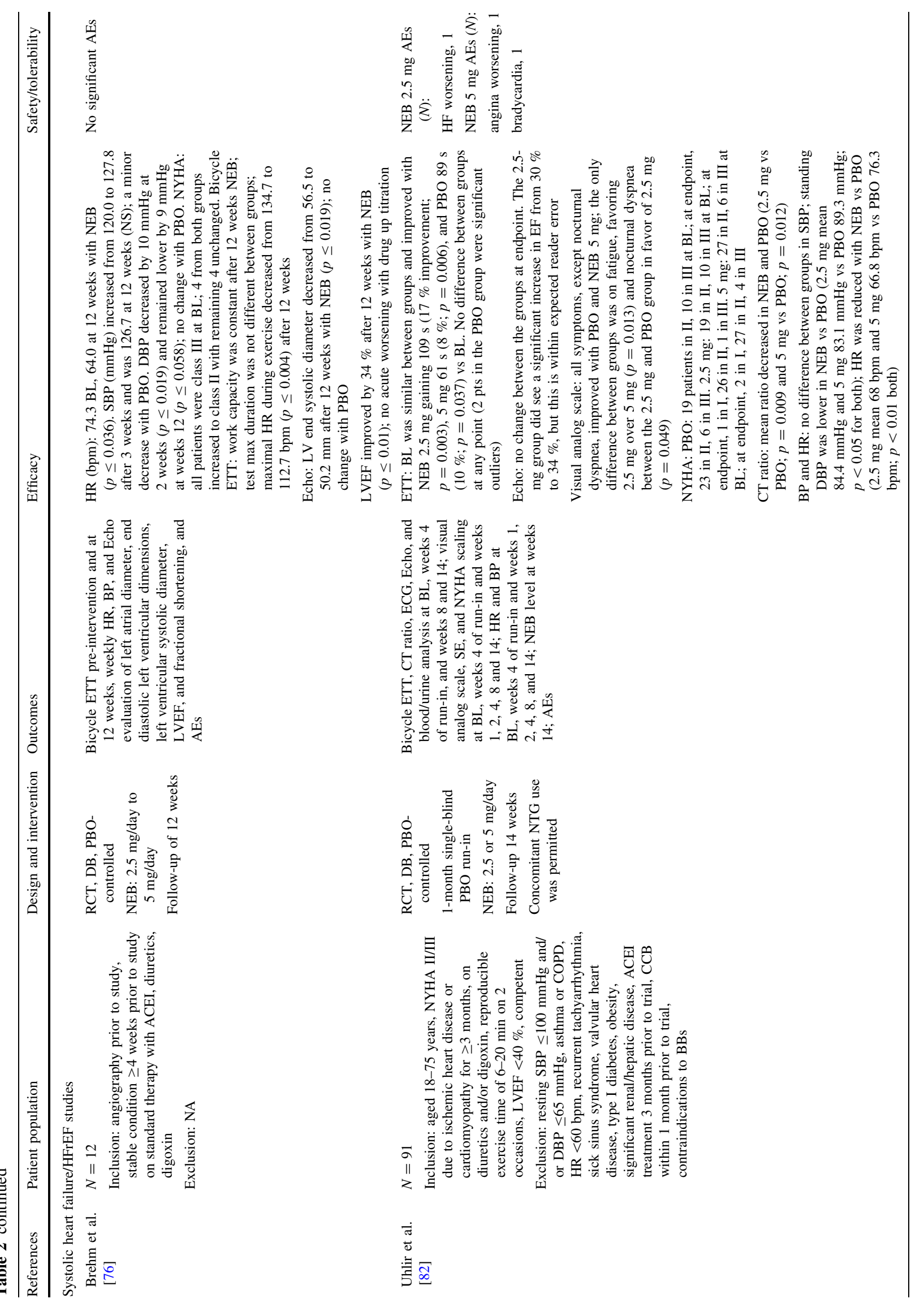




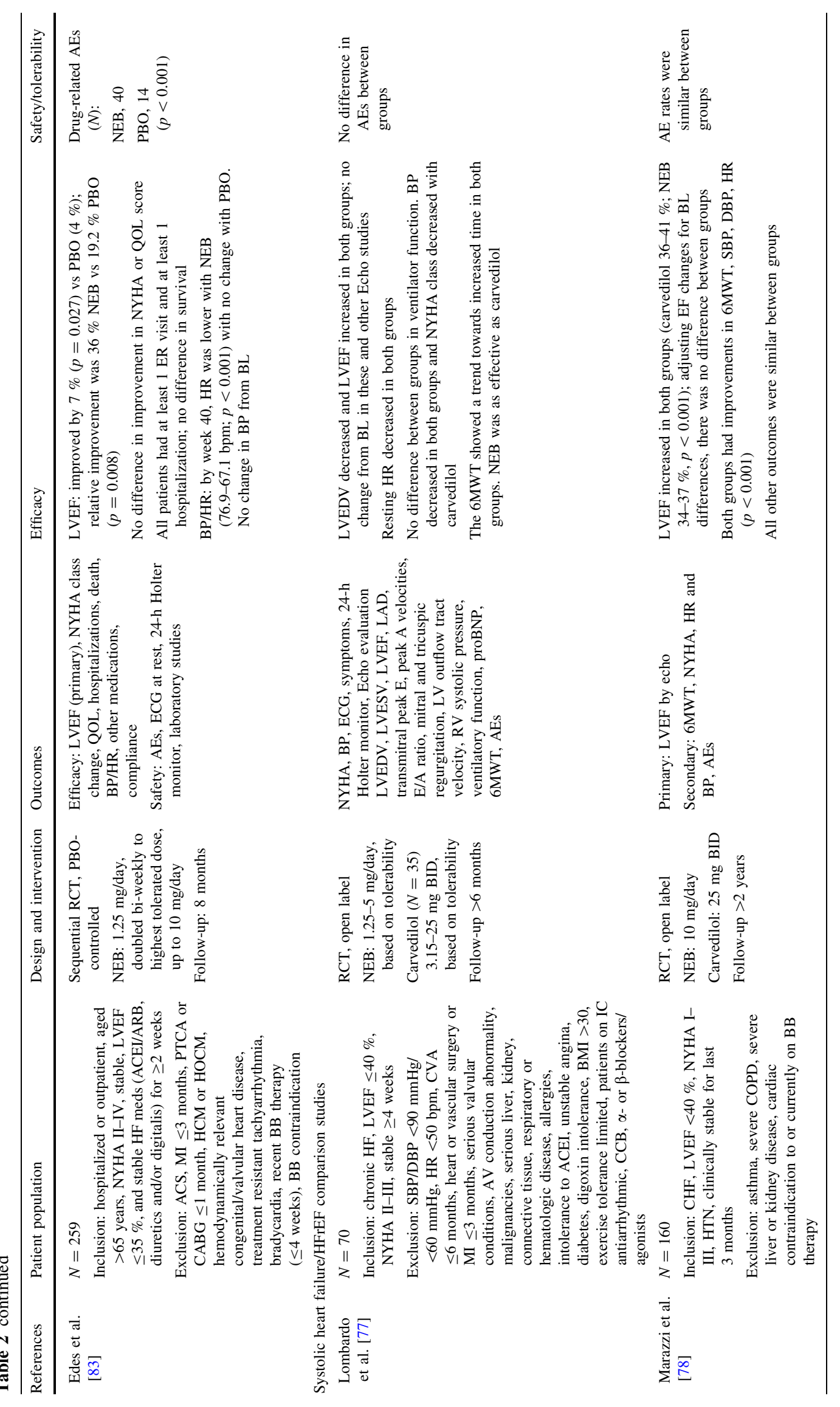




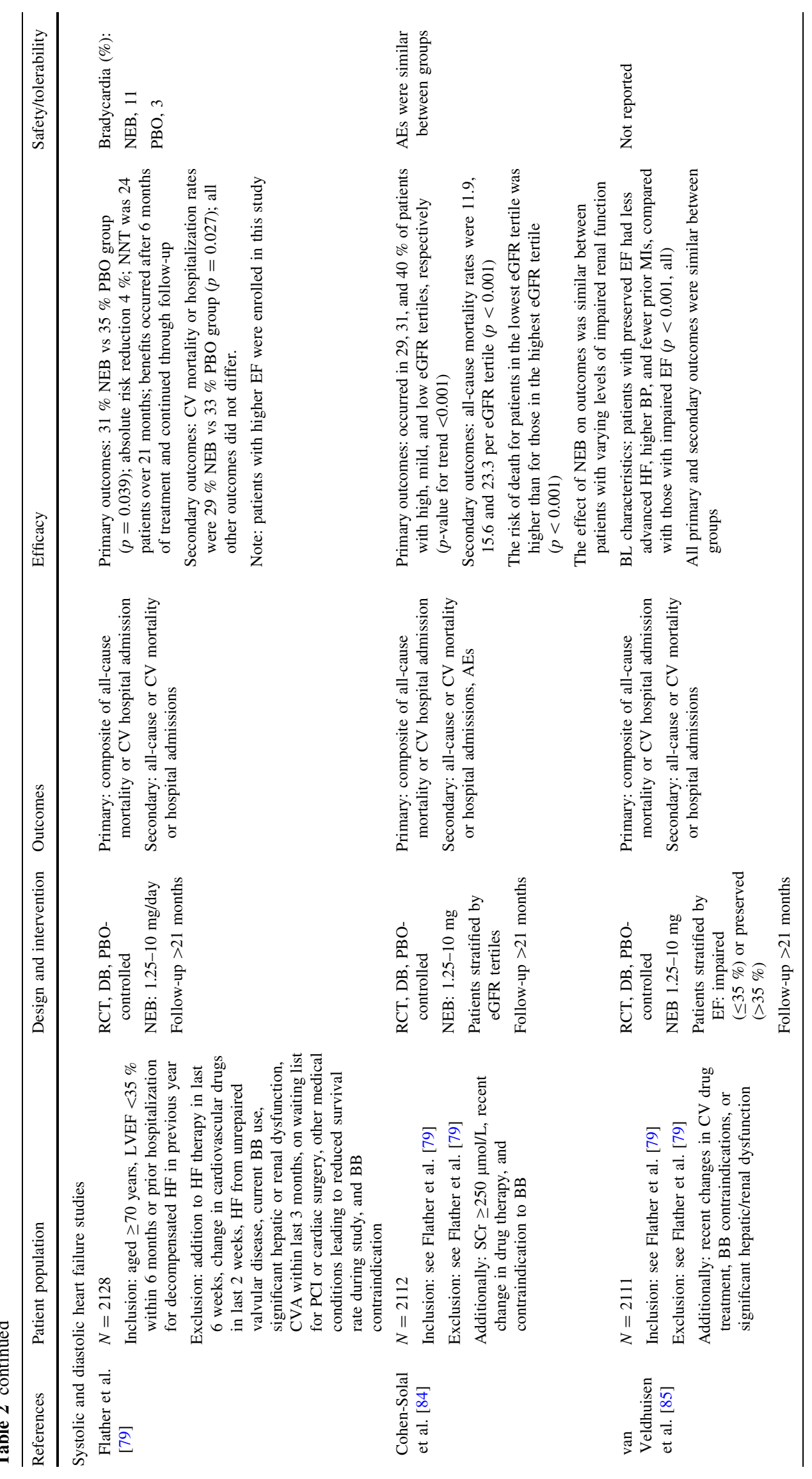




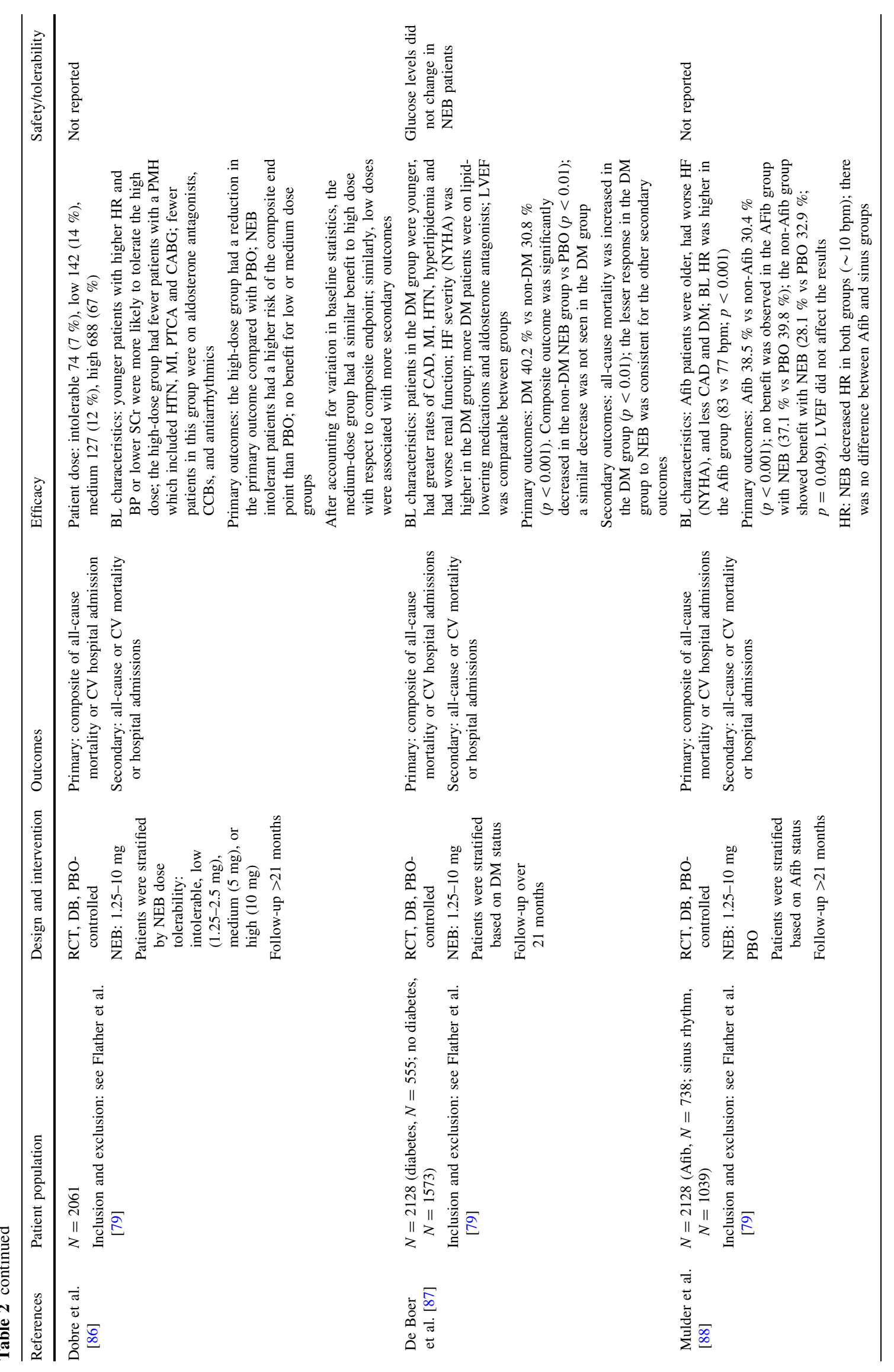




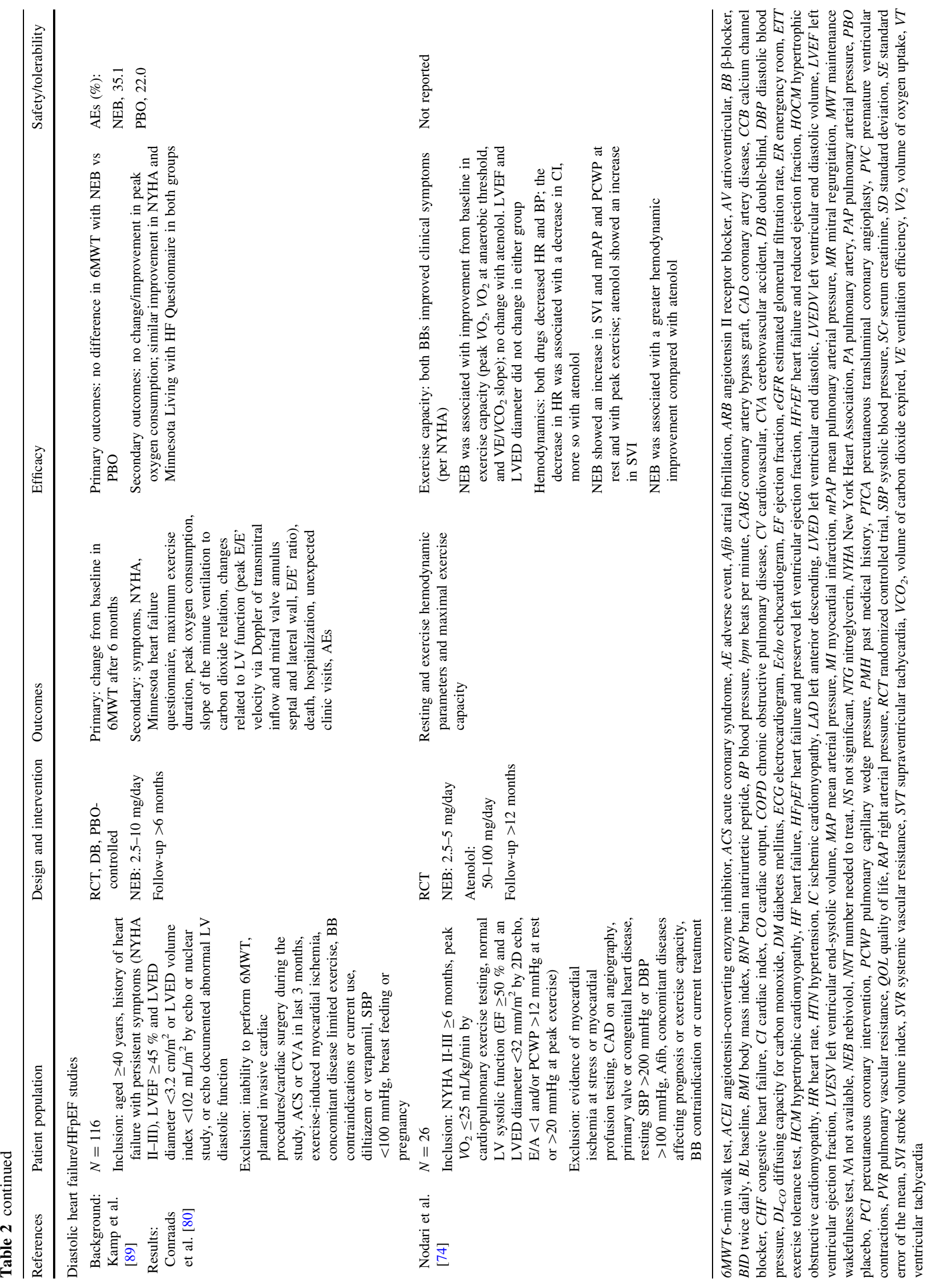


$(p \leq 0.001)$ and exercise performance $(p<0.0001)$ with nebivolol and bisoprolol [75].

\subsubsection{HF and Reduced Ejection Fraction (HFrEF)/Systolic $H F$}

Several studies in patients with HF suggest that nebivolol treatment may be beneficial due to the decrease in heart rate compared with placebo and a possible improvement in EF, New York Heart Association (NYHA) classification, and symptoms [72, 76-78]. Two of these studies describe an effect on LVEF similar to that of carvedilol [77, 78].

A large, randomized, placebo-controlled trial in elderly patients with a history of HF [ $\geq 70$ years of age; $68 \%$ with a history of coronary artery disease; $N=2128$ : SENIORS (Study of Effects of Nebivolol Intervention on Outcomes and Rehospitalization in Seniors With Heart Failure)] demonstrated a significantly lower risk of all-cause mortality or cardiovascular hospitalizations in nebivolol-treated patients versus placebo [odds ratio $(95 \% \mathrm{CI}): 0.86$ $(0.74-0.99) ; p=0.039$ ] [79]. However, the benefits of nebivolol in HF may be restricted to patients with HFrEF $(\mathrm{EF}<45 \%)$, as a 6-month, randomized (1:1) trial in patients with HFpEF (mean age 66 years; $N=116$ ) failed to show a difference in exercise capacity between nebivolol- and placebo-treated patients [80]. While current data suggest a benefit in elderly patients with HFrEF, most of whom had a history of coronary heart disease, more largescale, head-to-head, clinical outcome trials with bisoprolol, metoprolol succinate, and carvedilol are needed.

\subsubsection{HF and Preserved Left Ventricular Ejection Fraction (HFpEF)/Diastolic HF}

A benefit of nebivolol treatment in HFpEF is less clear than it is in patients with HFrEF. In addition to the study mentioned above, a study in which nebivolol treatment (titrated from 2.5 to $10 \mathrm{mg}$ ) over a 5 week period in patients with $\mathrm{HFpEF}$ resulted in no improvement in 6-min walk tests, peak oxygen consumption, NYHA classification, or Minnesota Living with HF questionnaire, versus placebo [80]. In contrast, two small-scale studies demonstrated a preferential hemodynamic effect with nebivolol vs atenolol and metoprolol, but clinical outcomes were not evaluated [74, 81]. At this time, the benefit of nebivolol use in patients with HFpEF is unproven and requires larger, randomized, clinical outcome trials.

\section{Nebivolol and Erectile Dysfunction}

The NO-mediated vasodilatory properties of nebivolol are possibly related to its benefits observed in erectile dysfunction (ED) over other $\beta$-blockers, which at worst have been associated with ED and at best have a neutral effect [90]. In a study of 44 men with hypertension treated with atenolol, metoprolol, or bisoprolol for over 6 months, switching to nebivolol treatment for 3 months resulted in an improvement in 20 out of $29(69 \%)$ patients who had ED, 11 of whom experienced a normalization of their erectile function [91]. In a randomized, 12-week, crossover trial of nebivolol and metoprolol in male outpatients with hypertension and no prior history of $\operatorname{ED}(N=48)$, metoprolol was associated with a decrease in mean erectile function subscores on the international index of erectile function scale $(p<0.05)$, while nebivolol had no effect [92]. In another 12-week trial of 131 hypertensive men randomized (1:1:1) to receive nebivolol, atenolol, or atenolol and the diuretic chlorthalidone, the mean number of satisfactory sexual intercourses per month declined by 47 and $56 \%$ in groups treated with atenolol and atenololchlorthalidone, respectively $(p<0.01$, both), while it remained constant in the group treated with nebivolol [93]. Finally, a large cross-sectional observational study of men with high-risk hypertension receiving $\beta$-blocker therapy revealed that nebivolol was associated with a lower prevalence of ED compared with other agents, but this association was limited to younger patients [94, 95].

\section{Pharmacoeconomics of Nebivolol Use}

Nebivolol is not yet available as a generic formulation in the US, which raises the question of its cost effectiveness compared with other $\beta$-blockers. There are no prospective studies that addressed this issue, but a retrospective claims analysis suggests that switching from $\geq 6$-month treatment with generic metoprolol to $\geq 6$ month treatment with nebivolol, although associated with a greater cost of treatment (US\$52 per month in 2011 dollars), is also associated with a $33 \%$ reduction in allcause hospitalizations, $60 \%$ reduction in hospitalizations due to cardiovascular causes, $7 \%$ reduction in monthly outpatient visits, and US\$111 monthly reduction in inpatient costs (all differences: $p<0.01$ ), leading to overall cost neutrality [96].

\section{Limitations}

The largest limitation in interpreting nebivolol trial data comes from an absence of outcomes trials in patients with hypertension, which limits our ability to assess the effect of nebivolol treatment on cardiovascular morbidity and mortality with any precision. Additionally, in the trial conducted in elderly patients with HF [79] in which a significant reduction of all-cause mortality and 
cardiovascular hospitalizations was observed with nebivolol versus placebo, the minimum follow-up period of 6 months was extended to 12 months by the Steering Committee due to an unexpectedly low rate of the combined primary event, observed in a blinded analysis [79]. This extension of the observation window was interpreted by the advisory panel of the US FDA as a potential source of bias [97]. An additional limitation is that there are currently few head-to-head trials comparing nebivolol with the core $\beta$-blockers used to treat HF. Consequently, nebivolol was not granted US approval for treatment of chronic $\mathrm{HF}$, despite the fact that it is used for that purpose in numerous other countries.

\section{Conclusion}

Nebivolol is a third-generation, long-acting and highly selective $\beta_{1}$ adrenoreceptor antagonist that also exhibits NO-mediated vasodilatory effects. It is currently FDA-approved for treatment of hypertension. While $\beta$-blockers are not recommended as first-line therapy for treatment of essential hypertension, nebivolol has shown comparable efficacy to ACEIs, ARBs, and CCBs in lowering SBP and DBP in adults with mild to moderate hypertension. However, $\beta$-blockers as a class have been associated with cardiovascular outcomes that are similar to or worse than currently recommended therapies. Due to its unique mechanism of action, nebivolol offers some central hemodynamic effects that differ from non-vasodilating $\beta$-blockers. Therefore, extrapolation of results from previous $\beta$-blocker trials may not be appropriate with regard to nebivolol, and large clinical outcome trials are needed to validate any difference in clinical outcomes.

While nebivolol does not currently carry an FDA approval for treatment of HF, current studies suggest that there may be clinical benefit for use in patients with HFrEF. Large comparison trials versus currently approved $\beta$-blockers are warranted. Alternatively, as with other $\beta$-blockers, data do not adequately support the routine use of nebivolol in patients with HFpEF. Nebivolol may be an appropriate alternative in patients who experience erectile dysfunction while on other $\beta$-blockers. Current research suggests that nebivolol may be a desirable treatment for specific indications, but further clinical investigation to determine its effects on cardiovascular morbidity and mortality is warranted.

Acknowledgments/Conflicts of interest J. Fongemie and E. FelixGetzik declare no conflicts of interest. Neither author has received financial compensation from any commercial interests. Funding for manuscript development was provided by Forest Laboratories LLC, an affiliate of Actavis Inc., New York, NY, to Prescott Medical Communications Group, Chicago, IL. The authors wish to thank Lynn
M. Anderson, PhD of Prescott Medical Communications Group for editorial and medical writing support.

\section{References}

1. Munzel T, Gori T. Nebivolol: the somewhat-different betaadrenergic receptor blocker. J Am Coll Cardiol. 2009;54:1491-9.

2. Pedersen ME, Cockcroft J. The vasodilatory beta-blockers. Curr Hypertens Rep. 2007;9:269-77.

3. Bristow M, Nelson P, Minobe W, Johnson C. Characterization of $\beta 1$-adrenergic receptor selectivity of nebivolol and various other beta-blockers in human myocardium. Am $\mathrm{J}$ Hypertens. 2005;18:A51-2.

4. Rosendorf C. Beta-blocking agents with vasodilator activity. J Hypertens. 1993;11:537.

5. Bowman A, Chen C, Ford G. Nitric oxide mediated venodilator effects of nebivolol. Br J Clin Pharmacol. 1994;38:199-204.

6. Cockcroft J, Chowienczyk P, Brett S, Chen C, Dupont A, Nueten L, Wooding S, Ritter J. Nebivolol vasodilates human forearm vasculature: Evidence for an L-arginine/NO-dependent mechanism. J Pharmacol Exp Ther. 1995;274:1067-71.

7. Dawes M, Brett SE, Chowienczyk PJ, Mant TG, Ritter JM. The vasodilator action of nebivolol in forearm vasculature of subjects with essential hypertension. Br J Clin Pharmacol. 1999;48:460-3.

8. Tzemos N, Lim PO, MacDonald TM. Nebivolol reverses endothelial dysfunction in essential hypertension: a randomized, double-blind, crossover study. Circulation. 2001;104:511-4.

9. Fonseca VA. Effects of beta-blockers on glucose and lipid metabolism. Curr Med Res Opin. 2010;26:615-29.

10. Schmidt A, Graf C, Brixius K, Scholze J. Blood pressure-lowering effect of nebivolol in hypertensive patients with type 2 diabetes mellitus: The YESTONO Study. Clin Drug Invest. 2007;27:841-9.

11. Ignjatovic V, Pavlovic S, Miloradovic V, Andjelkovic N, Davidovic G, Djurdjevic $P$, et al. Influence of different $\beta$-blockers on platelet aggregation in patients with coronary artery disease on dual antiplatelet therapy. J Cardiovasc Pharmacol Ther. 2015. doi: $10.1177 / 1074248415581175$.

12. Karabacak M, Dogan A, Aksoy F, Ozaydin M, Erdogan D, Karabacak P. Both carvedilol and nebivolol may improve platelet function and prothrombotic state in patients with nonischemic heart failure. Angiology. 2014;65:533-7.

13. Bystolic ${ }^{\circledR}$ (nebivolol tablets). Prescribing information. St. Louis: Forest Pharmaceuticals Inc, subsidiary of Forest Laboratories; 2011.

14. Montezano AC, Dulak-Lis M, Tsiropoulou S, Harvey A, Briones AM, Touyz RM. Oxidative stress and human hypertension: vascular mechanisms, biomarkers, and novel therapies. Can J Cardiol. 2015;31:631-41.

15. Arosio E, De Marchi S, Prior M, Zannoni M, Lechi A. Effects of nebivolol and atenolol on small arteries and microcirculatory endothelium-dependent dilation in hypertensive patients undergoing isometric stress. J Hypertens. 2002;20:1793-7.

16. Fratta Pasini A, Garbin U, Nava MC, Stranieri C, Davoli A, Sawamura $\mathrm{T}$, et al. Nebivolol decreases oxidative stress in essential hypertensive patients and increases nitric oxide by reducing its oxidative inactivation. J Hypertens. 2005;23:589-96.

17. Lekakis JP, Protogerou A, Papamichael C, Vamvakou G, Ikonomidis I, Fici F, et al. Effect of nebivolol and atenolol on brachial artery flow-mediated vasodilation in patients with coronary artery disease. Cardiovasc Drugs Ther. 2005;19:277-81.

18. Pasini AF, Garbin U, Stranieri C, Boccioletti V, Mozzini C, Manfro S, et al. Nebivolol treatment reduces serum levels of asymmetric dimethylarginine and improves endothelial dysfunction in essential hypertensive patients. Am $\mathrm{J}$ Hypertens. 2008;21:1251-7. 
19. Bouras G, Deftereos S, Tousoulis D, Giannopoulos G, Chatzis G, Tsounis D, et al. Asymmetric dimethylarginine (ADMA): a promising biomarker for cardiovascular disease? Curr Top Med Chem. 2013;13:180-200.

20. Kandavar R, Higashi Y, Chen W, Blackstock C, Vaughn C, Sukhanov S, et al. The effect of nebivolol versus metoprolol succinate extended release on asymmetric dimethylarginine in hypertension. J Am Soc Hypertens. 2011;5:161-5.

21. Nurnberger J, Keflioglu-Scheiber A, Opazo Saez AM, Wenzel RR, Philipp T, Schafers RF. Augmentation index is associated with cardiovascular risk. J Hypertens. 2002;20:2407-14.

22. Briasoulis A, Oliva R, Kalaitzidis R, Flynn C, Lazich I, Schlaffer $\mathrm{C}$, et al. Effects of nebivolol on aortic compliance in patients with diabetes and maximal renin angiotensin system blockade: the EFFORT study. J Clin Hypertens (Greenwich). 2013;15:473-9.

23. Serg M, Kampus P, Kals J, Zagura M, Zilmer M, Zilmer K, et al. Nebivolol and metoprolol: long-term effects on inflammation and oxidative stress in essential hypertension. Scand J Clin Lab Invest. 2012;72:427-32.

24. Kampus P, Serg M, Kals J, Zagura M, Muda P, Karu K, et al. Differential effects of nebivolol and metoprolol on central aortic pressure and left ventricular wall thickness. Hypertension. 2011;57:1122-8.

25. Safar ME, Blacher J, Pannier B, Guerin AP, Marchais SJ, Guyonvarc'h PM, et al. Central pulse pressure and mortality in endstage renal disease. Hypertension. 2002;39:735-8.

26. Vlachopoulos C, Aznaouridis K, Stefanadis C. Prediction of cardiovascular events and all-cause mortality with arterial stiffness: a systematic review and meta-analysis. J Am Coll Cardiol. 2010;55:1318-27.

27. Avolio AP, Van Bortel LM, Boutouyrie P, Cockcroft JR, McEniery $\mathrm{CM}$, Protogerou $\mathrm{AD}$, et al. Role of pulse pressure amplification in arterial hypertension: experts' opinion and review of the data. Hypertension. 2009;54:375-83.

28. Dhakam Z, Yasmin, McEniery C, Burton T, Wilkinson I, Brown M. A comparison of atenolol and nebivolol in isolated systolic hypertension. J Hypertens. 2008;26:351-6.

29. Mahmud A, Feely J. Beta-blockers reduce aortic stiffness in hypertension but nebivolol, not atenolol, reduces wave reflection. Am J Hypertens. 2008;21:663-7.

30. Redon J, Pascual-Izuel JM, Rodilla E, Vicente A, Olivan J, Bonet J, et al. Effects of nebivolol and atenolol on central aortic pressure in hypertensive patients: a multicenter, randomized, doubleblind study. Blood Press. 2014;23:181-8.

31. Werner TJ, Boutagy NE, Osterberg KL, Rivero JM, Davy KP. Singular and combined effects of nebivolol and lifestyle modification on large artery stiffness in hypertensive adults. Ther Adv Cardiovasc Dis. 2013;7:285-92.

32. Williams B, Lacy PS, Thom SM, Cruickshank K, Stanton A, Collier D, et al. Differential impact of blood pressure-lowering drugs on central aortic pressure and clinical outcomes: principal results of the Conduit Artery Function Evaluation (CAFE) study. Circulation. 2006;113:1213-25.

33. Dahlöf B, Sever PS, Poulter NR, Wedel H, Beevers DG, Caulfield $\mathrm{M}$, et al. Prevention of cardiovascular events with an antihypertensive regimen of amlodipine adding perindopril as required versus atenolol adding bendroflumethiazide as required, in the Anglo-Scandinavian Cardiac Outcomes Trial-Blood Pressure Lowering Arm (ASCOT-BPLA): a multicentre randomised controlled trial. Lancet. 2005;366:895-906.

34. Okamoto LE, Gamboa A, Shibao CA, Arnold AC, Choi L, Black BK, et al. Nebivolol, but not metoprolol, lowers blood pressure in nitric oxide-sensitive human hypertension. Hypertension. 2014;64:1241-7.

35. Stoschitzky K, Stoschitzky G, Pieske B, Wascher T. No evidence of nitrate tolerance caused by nebivolol. Ther Adv Cardiovasc Dis. $2014 ; 8: 40-4$.
36. Weber MA, Schiffrin EL, White WB, Mann S, Lindholm LH, Kenerson JG, et al. Clinical Practice Guidelines for the Management of Hypertension in the Community. A Statement by the American Society of Hypertension and the International Society of Hypertension. J Hypertens (Greenwich). 2014;16:14-26.

37. James PA, Oparil S, Carter BL, Cushman WC, Dennison-Himmelfarb C, Handler J, et al. 2014 evidence-based guideline for the management of high blood pressure in adults: report from the panel members appointed to the Eighth Joint National Committee (JNC 8). JAMA. 2014;311:507-20.

38. Dahlöf B, Devereux RB, Kjeldsen SE, Julius S, Beevers G, de Faire U, et al. Cardiovascular morbidity and mortality in the Losartan Intervention For Endpoint reduction in hypertension study (LIFE): a randomised trial against atenolol. Lancet. 2002;359:995-1003.

39. Lindholm LH, Carlberg B, Samuelsson O. Should $\beta$ blockers remain first choice in the treatment of primary hypertension? A meta-analysis. Lancet. 2005;366:1545-53.

40. Wiysonge CSU, Bradley HA, Mayosi BM, Maroney RT, Mbewu A, Opie L, et al. Beta-blockers for hypertension. Cochrane Database Syst Rev. 2007;1:1-47.

41. Cockcroft JR, Pedersen ME. Beta-blockade: benefits beyond blood pressure reduction? J Clin Hypertens (Greenwich). 2012;14:112-20.

42. Weiss R, Weber M, Carr A, Sullivan W. A randomized, doubleblind, placebo-controlled parallel-group study to assess the efficacy and safety of nebivolol, a novel b-blocker, in patients with mild to moderate hypertension. J Clin Hypertens. 2007;9:667-76.

43. Saunders E, Smith W, DeSalvo K, Sullivan W. The efficacy and tolerability of nebivolol in hypertensive african american patients. J Clin Hypertens. 2007;9:866-75.

44. Greathouse M. Nebivolol efficacy and safety in patients with stage I-II hypertension. Clin Cardiol. 2010;33:E20-7.

45. Weiss RJ, Saunders E, Greathouse M. Efficacy and tolerability of nebivolol in stage I-II hypertension: a pooled analysis of data from three randomized, placebo-controlled monotherapy trials. Clin Ther. 2011;33:1150-61.

46. Germino FW, Lin Y, Pejovic V, Bowen L. Efficacy and tolerability of nebivolol: does age matter? A retrospective analysis of three randomized, placebo-controlled trials in stage I-II hypertension. Ther Adv Cardiovasc Dis. 2012;6:185-99.

47. Manrique C, Whaley-Connell A, Sowers JR. Nebivolol in obese and non-obese hypertensive patients. J Clin Hypertens (Greenwich). 2009;11:309-15.

48. Giles TD, Khan BV, Lato J, Brener L, Ma Y, Lukic T. Nebivolol monotherapy in younger adults (younger than 55 years) with hypertension: a randomized, placebo-controlled trial. J Clin Hypertens (Greenwich). 2013;15:687-93.

49. Punzi H, Lewin A, Lukic T, Goodin T, Wei C. Efficacy and safety of nebivolol in Hispanics with stage I-II hypertension: a randomized placebo-controlled trial. Ther Adv Cardiovasc Dis. 2010;4:349-57.

50. Grassi G, Trevano FQ, Facchini A, Toutouzas T, Chanu B, Mancia G. Efficacy and tolerability profile of nebivolol vs atenolol in mild-to-moderate essential hypertension: results of a double-blind randomized multicentre trial. Blood Press. 2003;12:35-40.

51. Lacourcière Y, Lefebvre J, Poirier L, Archambault F, Arnott W. A double-blind crossover comparison of nebivolol and lisinopril in the treatment of ambulatory hypertension. Am $\mathrm{J}$ Ther. 1994;1:74-80.

52. Mazza A, Gil-Extremera B, Maldonato A, Toutouzas T, Pessina AC. Nebivolol vs amlodipine as first-line treatment of essential arterial hypertension in the elderly. Blood Press. 2002;11:182-8.

53. Van Bortel L, Bulpitt C, Fici F. Quality of life and antihypertensive effect with nebivolol and losartan. Am J Hypertens. 2005;18:1060-6. 
54. Van Nueten L, Taylor F, Robert J. Nebivolol vs atenolol and placebo in essential hypertension: a double-blind randomised trial. J Hum Hypertens. 1998;12:135-40.

55. Van Nueten L, Lacourcière Y, Vyssoulis G, Korlipara K, Marcadet DM, Dupont AG, et al. Nebivolol versus nifedipine in the treatment of essential hypertension: a double-blind, randomized, comparative trial. Am J Ther. 1998;5:237-43.

56. Chobanian AV, Bakris GL, Black HR, Cushman WC, Green LA, Izzo JL Jr, et al. Seventh report of the Joint National Committee on Prevention, Detection, Evaluation, and Treatment of High Blood Pressure. Hypertension. 2003;42:1206-52.

57. Gu Q, Burt VL, Dillon CF, Yoon S, Gu Q, Dillon CF, et al. Trends in antihypertensive medication use and blood pressure control among United States adults with hypertension: the National Health And Nutrition Examination Survey, 2001 to 2010. Circulation. 2012;126:2105-14.

58. Papademetriou V. Comparison of Nebivolol monotherapy versus nebivolol in combination with other antihypertensive therapies for the treatment of hypertension. Am J Cardiol. 2009;103:273-8.

59. Neutel JM, Smith DH, Gradman AH. Adding nebivolol to ongoing antihypertensive therapy improves blood pressure and response rates in patients with uncontrolled stage I-II hypertension. J Hum Hypertens. 2010;24:64-73.

60. Weber MA, Basile J, Stapff M, Khan B, Zhou D. Blood pressure effects of combined beta-blocker and angiotensin-converting enzyme inhibitor therapy compared with the individual agents: a placebo-controlled study with nebivolol and lisinopril. J Clin Hypertens (Greenwich). 2012;14:588-92.

61. Weiss RJ, Stapff M, Lin Y. Placebo effect and efficacy of nebivolol in patients with hypertension not controlled with lisinopril or losartan: a phase IV, randomized, placebo-controlled trial. Am J Cardiovasc Drugs. 2013;13:129-40.

62. Giles TD, Weber MA, Basile J, Gradman AH, Bharucha DB, Chen W, et al. Efficacy and safety of nebivolol and valsartan as fixed-dose combination in hypertension: a randomised, multicentre study. Lancet. 2014;383:1889-98.

63. Yancy CW, Jessup M, Bozkurt B, Butler J, Casey DE Jr, Drazner $\mathrm{MH}$, et al. $2013 \mathrm{ACCF} / \mathrm{AHA}$ guideline for the management of heart failure: a report of the American College of Cardiology Foundation/American Heart Association Task Force on practice guidelines. Circulation. 2013;128:e240-327.

64. Mason R, Giles T, Sowers J. Evolving mechanisms of action of beta blockers: focus on nebivolol. J Cardiovasc Pharmacol. 2009:54:123-8.

65. Klapholz M. $\beta$-blocker use for the stages of heart failure. Mayo Clin Proc. 2009;84:718-29.

66. Fonarow GC, Abraham WT, Albert NM, Stough WG, Gheorghiade M, Greenberg BH, et al. Factors identified as precipitating hospital admissions for heart failure and clinical outcomes: findings from OPTIMIZE-HF. Circ Heart Fail. 2008;168:847-54.

67. Fonarow GC, Heywood JT, Heidenreich PA, Lopatin M, Yancy $\mathrm{CW}$. Temporal trends in clinical characteristics, treatments, and outcomes for heart failure hospitalizations, 2002 to 2004: findings from Acute Decompensated Heart Failure National Registry (ADHERE). Am Heart J. 2007;153:1021-8.

68. Chatterjee S, Biondi-Zoccai G, Abbate A, D'Ascenzo F, Castagno D, Van Tassell B, et al. Benefits of beta blockers in patients with heart failure and reduced ejection fraction: network metaanalysis. BMJ. 2013;346:f55.

69. Howlett JG. Nebivolol: vasodilator properties and evidence for relevance in treatment of cardiovascular disease. Can J Cardiol. 2014;30:S29-37.

70. Pedersen ME, Cockcroft JR. What is the role, if any, for betablockers as initial therapy for uncomplicated hypertension? Curr Opin Cardiol. 2009;24:325-32.
71. Kamp O, Sieswerda GT, Visser CA. Comparison of effects on systolic and diastolic left ventricular function of nebivolol versus atenolol in patients with uncomplicated essential hypertension. Am J Cardiol. 2003;92:344-8.

72. Brune S, Schmidt T, Tebbe U, Kreuzer H. Hemodynamic effects of nebivolol at rest and on exertion in patients with heart failure. Angiology. 1990;41:696-701.

73. Triposkiadis F, Giamouzis G, Kelepeshis G, Sitafidis G, Skoularigis J, Demopoulos V, et al. Acute hemodynamic effects of moderate doses of nebivolol versus metoprolol in patients with systolic heart failure. Int J Clin Pharmacol Ther. 2007;45:71-7.

74. Nodari S, Metra M. Dei Cas L. $\beta$-Blocker treatment of patients with diastolic heart failure and arterial hypertension. A prospective, randomized, comparison of the long-term effects of atenolol vs. nebivolol. Eur J Heart Fail. 2003;5:621-7.

75. Contini M, Apostolo A, Cattadori G, Paolillo S, Iorio A, Bertella E, et al. Multiparametric comparison of CARvedilol, vs. NEbivolol, vs. BIsoprolol in moderate heart failure: the CARNEBI trial. Int J Cardiol. 2013;168:2134-40.

76. Brehm B, Wolf S, Gorner S, Buck-Muller N, Risler T. Effect of nebivolol on left ventricular function in patientswith chronic heart failure: a pilot study. Eur Heart J. 2002;4:757-63.

77. Lombardo R, Reina C, Abrignani M, Rizzo P, Braschi A, De Castro S. Effects of nebivolol versus carvedilol on left ventricular function in patients with chronic heart failure and reduced left ventricular systolic function. Am J Cardiovas Drugs. 2006;6:259-63.

78. Marazzi G, Volterrani M, Caminiti G, Iaia L, Massaro R, Vitale $\mathrm{C}$, et al. Comparative long term effects of nebivolol and carvedilol in hypertensive heart failure patients. J Card Fail. 2011;17:703-9.

79. Flather MD, Shibata MC, Coats AJ, Van Veldhuisen DJ, Parkhomenko A, Borbola J, et al. Randomized trial to determine the effect of nebivolol on mortality and cardiovascular hospital admission in elderly patients with heart failure (SENIORS). Eur Heart J. 2005;26:215-25.

80. Conraads VM, Metra M, Kamp O, De Keulenaer GW, Pieske B, Zamorano $\mathrm{J}$, et al. Effects of the long-term administration of nebivolol on the clinical symptoms, exercise capacity, and left ventricular function of patients with diastolic dysfunction: results of the ELANDD study. Eur J Heart Fail. 2012;14:219-25.

81. Vinereanu D, Gherghinescu C, Ciobanu AO, Magda S, Niculescu N, Dulgheru R, et al. Reversal of subclinical left ventricular dysfunction by antihypertensive treatment: a prospective trial of nebivolol against metoprolol. J Hypertens. 2011;29:809-17.

82. Uhlir O, Dvorak I, Gregor R, Malek I, Spinarova L, Vojacek J, Van Nueten L. Nebivolol in the treatment of cardiac failure: a doubleblind controlled clinical trial. J Cardiac Fail. 1997;3:271-6.

83. Edes I, Gasior Z, Wita K. Effects of nebivolol on left ventricular function in elderly patients with chronic heart failure: results of the ENECA study. Eur J Heart Fail. 2005;7:631-9.

84. Cohen-Solal A, Kotecha D, van Veldhuisen DJ, Babalis D, Bohm $\mathrm{M}$, Coats AJ, et al. Efficacy and safety of nebivolol in elderly heart failure patients with impaired renal function: insights from the SENIORS trial. Eur J Heart Fail. 2009;11:872-80.

85. van Veldhuisen DJ, Cohen-Solal A, Bohm M, Anker SD, Babalis $\mathrm{D}$, Roughton $\mathrm{M}$, et al. Beta-blockade with nebivolol in elderly heart failure patients with impaired and preserved left ventricular ejection fraction: Data From SENIORS (Study of Effects of Nebivolol Intervention on Outcomes and Rehospitalization in Seniors With Heart Failure). J Am Coll Cardiol. 2009;53:2150-8.

86. Dobre D, van Veldhuisen DJ, Mordenti G, Vintila M, HaaijerRuskamp FM, Coats AJ, et al. Tolerability and dose-related effects of nebivolol in elderly patients with heart failure: data from the Study of the Effects of Nebivolol Intervention on 
Outcomes and Rehospitalisation in Seniors with Heart Failure (SENIORS) trial. Am Heart J. 2007;154:109-15.

87. de Boer RA, Doehner W, van der Horst IC, Anker SD, Babalis D, Roughton $\mathrm{M}$, et al. Influence of diabetes mellitus and hyperglycemia on prognosis in patients $>$ or $=70$ years old with heart failure and effects of nebivolol (data from the Study of Effects of Nebivolol Intervention on Outcomes and Rehospitalization in Seniors with heart failure [SENIORS]). Am J Cardiol. 2010;106(78-86):e1.

88. Mulder BA, van Veldhuisen DJ, Crijns HJ, Bohm M, CohenSolal A, Babalis D, et al. Effect of nebivolol on outcome in elderly patients with heart failure and atrial fibrillation: insights from SENIORS. Eur J Heart Fail. 2012;14:1171-8.

89. Kamp O, Metra M, De Keulenaer GW, Pieske B, Conraads V, Zamorano $\mathrm{J}$, et al. Effect of the long-term administration of nebivolol on clinical symptoms, exercise capacity and left ventricular function in patients with heart failure and preserved left ventricular ejection fraction: background, aims and design of the ELANDD study. Clin Res Cardiol. 2010;99:75-82.

90. La Torre A, Giupponi G, Duffy D, Conca A, Catanzariti D. Sexual dysfunction related to drugs: a critical review. Part IV: cardiovascular drugs. Pharmacopsychiatry. 2015;48:1-6.

91. Doumas M, Tsakiris A, Douma S, Grigorakis A, Papadopoulos A, Hounta A, et al. Beneficial effects of switching from beta- blockers to nebivolol on the erectile function of hypertensive patients. Asian J Androl. 2006;8:177-82.

92. Brixius K, Middeke M, Lichtenthal A, Jahn E, Schwinger RH. Nitric oxide, erectile dysfunction and beta-blocker treatment (MR NOED study): benefit of nebivolol versus metoprolol in hypertensive men. Clin Exp Pharmacol Physiol. 2007;34:327-31.

93. Boydak B, Nalbantgil S, Fici F, Nalbantgil I, Zoghi M, Ozerkan $\mathrm{F}$, et al. A randomised comparison of the effects of nebivolol and atenolol with and without chlorthalidone on the sexual function of hypertensive men. Clin Drug Investig. 2005;25:409-16.

94. Cordero A, Bertomeu-Martinez V, Mazon P, Facila L, BertomeuGonzalez V, Conthe P, et al. Erectile dysfunction in high-risk hypertensive patients treated with beta-blockade agents. Cardiovasc Ther. 2010;28:15-22.

95. Cordero A, Bertomeu-Martinez V, Mazon P, Facila L, GonzalezJuanatey JR, Cordero A, et al. Erectile dysfunction may improve by blood pressure control in patients with high-risk hypertension. Postgrad Med. 2010;122:51-6.

96. Chen S, Tourkodimitris S, Lukic T. Economic impact of switching from metoprolol to nebivolol for hypertension treatment: a retrospective database analysis. J Med Econ. 2014;17:685-90.

97. Stiles S. Panel to FDA: Nebivolol Shouldn't Be Approved for Chronic Heart Failure. 2010. Available from: http://www. medscape.com/viewarticle/715059. Cited 13 Jan 2010. 